\title{
ON THE APPLICATION OF WATER PRESSURE TO DRIVING MACHINERY AND WORKING SHOP TOOLS.
}

BY Mr. RALPH H. TWEDDELL, OF LONDON.

The extension which has taken place in the application of Hydraulic Power to riveting is now considerable, and is a confirmation of the views expressed by the writer in a former paper as to the practicability of this principle; there are at the present time more than a hundred hydraulic riveting machines in regular work in this country, each exerting a closing pressure of from 25 to 40 tons, and putting in daily from 1500 to 2000 rivets each.

An objection has previously been raised that these machines involve a certain loss of power by the use of water at a high pressure through the first portion of the stroke in riveting, through which a lower pressure vould be sufficient; but in reference to this objection it has to be observed that, when the accumulator capacity bears a sufficiently small proportion to that of the riveter cylinder, the advantage gained by utilising the momentum of the falling accumulator at the end of the stroke of the ram more than counterbalances the above loss. The closing pressure on the rivet head in the machines on the writer's plan is consequently considerably greater than that due to the pressure per square inch in the accumulator, and such a machine, while exerting nominally a pressure of 40 tons on the rivet, gives in many cases nearly 60 tons closing pressure. But this compensating advantage does not occur with a hydraulic riveter worked at a low initial pressure, or even with a high pressure when the quantity of water drawn from the accumulator at each stroke of the ram bears no considerable proportion to its total contents; because the accumulator has not then sufficient extent of fall to produce the combination of a blow 
with a dead pressure which has been found so effective and essential in riveting, especially for the heavier class of boilers.

An example of the Stationary Hydraulic Riveter on this plan is shown in Fig. 1, Plate 51, which represents a machine of the largest size, that is now at work riveting large marine boilers at Messrs. Palmer's, Newcastle-on-Tyne. The riveter A is here shown riveting a large high-pressure marine boiler $\mathrm{B}, 12 \mathrm{ft}$. diameter and $11 \mathrm{ft}$. high, with $1 \frac{1}{8}$ in. plates ; this is received in a pit $\mathrm{C}$, in which the riveter is also more than half sunk, so that only an ordinary height of machine of about $5 \mathrm{ft}$. is above the ground line $D$. This arrangement saves head room in the shop, and a platform and ladder $\mathrm{E}$ beneath the traveller give easy access to the die on the holder-up $\mathrm{F}$; but no person is required to be inside when the machine is working, as the rivets are put in from the outside. By means of this machine the boiler can be riveted straight off when plated.

As there is a quantity of boiler work that can be done best by taking the riveter to it, or cannot conveniently be done by any form of fixed riveting machine, the arrangement shown in Fig. 2, Plate 52, is used in such cases, consisting of a Portable Hydraulic Riveter, carried upon a bracket or column, and balanced. This is shown in the drawing applied to rivet together the llanged rings of the internal flue $A$ of a boiler. For this class of work the portable riveter $B$ has a shoe $C$ cast on the cylinder, which works vertically up and down upon the slipper-guide on the casting $D$ attached to a column or wall $\mathbf{E}$. The riveter is not quite balanced by the weight $F$ attached to the lever $G$, which works on a centre $H$ in the bracket $\mathrm{D}$; and this centre is the only fixed connection between the portable riveter and the bracket. The riveter being slightly heavier, all that the man has to do to clear the rivet head is to exert a lifting pressure equal to the difference between the weight of the riveter and the balance weight acting through the lever; this dispenses with the necessity which at present exists of lowering the whole tube to clear the rivet head. The man then releasing his hold of the machine, it falls with the cupping die on the rivet head; and water being admitted under the ram $J$, the lever $K$ rises and 
closes the rivet, without any jerking of the tube or any vibration or strain upon the crane chains. This arrangement takes up no shop room, since the greater part may be embedded in the wall; and it is equally suitable for riveting the front end on a boiler, when the end is attached to the shell by an outside angle-iron. This machine has a cylinder 6 in. diameter, and effectually accomplishes the small residue of work left undone by the fixed riveting machine; and as a rule it involves little extra cost for accumulator and pumps.

The extended adoption of high-pressure hydraulic tools at many works where hydraulic power is already in use up to the ordinary pressure of $700 \mathrm{lb}$. per sq. in., or where the low pressure of the waterworks mains is used, has rendered necessary some simple means of converting the existing pressure into the higher one required for any special tool or machine. Such an apparatus is shown in the Intensifying Accumulator, Fig. 10, Plate 58, in which the pipe A conveys the low-pressure water into the cylinder $B$, and the pressure on the piston $\mathrm{C}$ acting upon the smaller ram $\mathrm{D}$ gives an increased pressure to the water in the second oylinder $E$ in proportion to the relative areas of the piston $\mathrm{C}$ and $\mathrm{ram} \mathrm{D}$. In this case the piston is $19 \mathrm{in}$. diameter and the ram $3 \frac{3}{4} \mathrm{in}$., and a pressure of $60 \mathrm{lb}$. per sq. in. on the piston gives $1540 \mathrm{lb}$. per sq. in. on the ram. The water from the pumps enters through the inlet $G$, and passes out at $H$ to the machine to be worked by it; no water is consumed from the low-pressure cylinder, but it is simply driven back by the force pumps into the low-pressure accumulator or mains.

In Fig. 3, Plate 53, is shown the general arrangement of the Hydraulic Riveting Plant used on a large girder bridge carrying Primrose Street over the metropolitan extension of the Great Eastern Railway; and the experience of its working has been so successful that similar plant is being constructed for riveting the greater portion of the large roof at the extension station. The furnace $A$ both heats the rivets and raises all the steam required by the boiler $B$ to drive the engine $C$, which works the pumps $D$; these force the water into the 
accumulator $\mathrm{F}$, whence it is transmitted through the pipe $F$ to the riveter, and is returned after use to the tank $G$. There is all the necessary gearing for traversing, swinging, hoisting, and altering radius of jib; and the crane is also arranged to lift any weight up to about 1 ton. Thas it not only rivets up, but also assists in the construction of the bridge. This riveting machine has put in at the Primrose Street bridge $300 \frac{3}{4}$-in. rivets per hour, and 120 to 150 1-in. rivets per hour, through eight thicknesses of $\frac{1}{2}$ in. plate. Punching and shearing machines are combined with it when required, and are found very convenient. From the experience of the working of this machine, though only on its first trial, the writer has come to the conclusion that one set of hand riveters in addition to the machine will do the work of six sets without it; and for the heavy work especially, will do it much better. The rivets most difficult to be got at are not generally of the greatest importance, and a judicious combination of hand and machine work would in the writer's opinion very considerably reduce the cost and lessen the weight of bridge work, more especially if oval rivets were used; and the closing of these can be best done by hydraulic pressure. For many suggestions as to this application the writer is indebted to the late Mr. G. H. Asbbee.

In Fig. 4, Plate 54, is shown a proposed arrangement for doing work on bridges \&c. in situations difficult of access or up-country places, where the cost and difficulty of transporting the heavy weights required for ordinary accumulators would be too great. A light galvanised tank $A$ is placed at any convenient elevation, fixed on any adjacent building or height; and the pipe $B$ conveys water from the tank to the large piston of the intensifying accumulator $\mathrm{C}$; the high pressure is obtained by pumping water from the pump $D$ into the small end $E$ of the accumulator, whence it is taken by a high-pressure pipe $F$ to the riveter $G$ or other machines on the ground. The pumps are driven by an ordinary portable engine, or can be attached by gearing to a gin worked by cattle. The accumulator itself is on wheels for the convenience of transport. As there is no consumption of water from the low-pressure tank, a very much smaller tank than would at first 
appear necessary is required; for assuming that only $20 \mathrm{lb}$. per sq. in. is obtained on the low-pressure side, an elevation of a little over $40 \mathrm{ft}$. will give this pressure, and the tank once filled requires no refilling, as there is no loss except that due to evaporation and any slight leakage; consequently a tank of only $4 \frac{1}{2} \mathrm{cub}$. ft. capacity will keep a 6 in. portable riveter in full work using a pressure of $1500 \mathrm{lb}$. per sq. in.

In extending the application of hydraulic power, the next thing after the application to riveting was to do away with the skilled labour required in the Hlanging and bending of plates. This is not easy to accomplish, and after long continued trials the writer has found that flanging by solid dies has many disadrantages and involves great cost in dies and moulds; and he has come to the conclusion that the plan of hydraulic flanging press with a hollow ring die, by M. Gustave Piedbcouf of Jupille near Liège, is the best adapted for this purpose.

In Fig. 5, Plate 55, is shown a sectional elevation of this Hydraulic Flanging Machine. The cylinder A is connected to an accumulator loaded to abont $1500 \mathrm{lb}$. per sq. in., and the water acting on the ram $B$ raises the moving table $C$, carrying with it the matrix or annular die $D$, which is supported on small columns E; some of these are not bolted to the table, but only slipped in, and can thus be easily taken out when the plate $P$ has been flanged and requires to be removed. The block $G$ is attached to the top frame, and corresponds to the matrix; and although in this example a round plate is shown, the block and matrix can be made to any required shape. The small auxiliary cylinders $H$ carry on their rams a table $K$, suitable openings being made in the main table $\mathrm{C}$ to allow of the rams $\mathrm{H}$ moving freely up and down independently. The full black line in the drawing shows a plate $\mathbf{P}$ at the moment before completion; and the dotted lines show it just completed and detached from the block $G$, and ready to be removed by taking out one of the columns $\mathrm{E}$. To flange a plate after heating it, the main table $\mathrm{C}$ and small table $\mathrm{K}$ are let down to their bottom position; and the plate being placed on the table $\mathrm{K}$, 
pressure is admitted to the cylinders $H$, causing this table to rise up and hold the plate against the block $G$; this prevents all buckling and risk of unequal fianging. Pressure is then admitted to the main cylinder $\mathrm{A}$, cansing the main table $\mathrm{C}$ carrying the matrix $D$ to rise; the matrix catches the edge of the plate $P$ and forces it over the block $G$, as shown. The water is then let out of the cylinders, and the plate is done, the whole operation occupying only about half a minate.

In Figs. 6 and 7, Plate 56, is shown an application of hydranlic pressure to a machine for Shearing Chain Cables, for cutting into scrap or for taking out links in testing \&c. Shearing by hydraulic pressure is not new, but this design has some novel features. One of the conditions being that the cable is to be cut in one stroke, this is accomplished, not indeed at one moment of time, but by stepping the knife A, which allows the area of the cylinder to be halved, at the same time doubling the stroke although using the same amount of water. The pressure employed being as much as $2000 \mathrm{Ib}$. per sq. in., this reduction of diameter is a great consideration towards obtaining a strong cylinder with a moderate quantity of metal. The drawback gear $\mathrm{B}$ is also hydraulic, and the machines have two ends, so that every intermediate size of cable from $3 \frac{1}{2}$ to $\frac{1}{2}$ in. can be cut without changing the knives or injuring an unnecessary number of adjoining links. Several of these machines are working in public testing establishments in this country.

In Figs. 8 and 9, Plates 57 and 58, is shown one of the writer's Hydraulic Punching Shearing and Angle-Bar Cutting machines, which dispenses with belting and gearing. This machine consists of three parts, each of which can be ased independently of the others, and can be placed in different parts of the yard if desired. $A$ is for angle and bar cutting, $B$ for shearing, forging, and stamping, and $C$ for panching. The inlet and exhaust valves $V$ are worked by hand from above or at the side, or by a treadle on the ground under the foot of the attendant; $E, H$ and $P$ represent the exhaust pipes, the pressure pipes to the drawback gear, and the inlet pipes from the main. Suitable provision is made to prevent the rams from coming too far down; and the stroke can be regulated to a 
nicety, so as to waste no power when cutting or punching thinner plates. This is a valuable point, and as the entire movement and stopping or starting of the machine is in the hands of the attendant, the risk of blind holes from the punch coming down too soon is obviated. This machine has a 12 in. cylinder, and has punched $1 \frac{1}{2}$ in. holes in 1 in. plates, and sheared $1 \frac{1}{2}$ in. plates and angles $5 \times 5 \times \frac{1}{2}$ in. As a speed of over 30 strokes per min. can be obtained, there is no difficulty in punching holes as fast as is possible by men continuously, which is supposed to be about 20 to 22 per min. No breakdown of the machine is likely to occur, since if too heary a cut or punching is attempted the ram stops as soon as the accumulator pressure is reached; and if one should break down, the others are not affected as in geared machines. The object of making these machines of such large power is to enable dies and punches to be attached for punching large openings in thin plates, and for stamping and moulding; hence all the dies and knife holders are so made as to be readily detached, and the necessary moulds applied for forging and stamping. The knives can be placed at any angle, slots being provided in the dies for allowing them to be turned round.

The Hydraulic Corrugating Press shown in Figs. 11 and 12, Plate 59, is employed to corrugate sheet iron for roofing purposes, and to stamp fence pillars and posts; it corrugates plates $12 \mathrm{ft}$. long and from $\frac{1}{16}^{\frac{1}{6}}$ to $\frac{3}{4}$ in. thick, and would do larger sizes. The bedplate A carries four columns $B$, which support the end frames or girders $C$. The rams $D$ are parts of these; and the cylinders $E$ which move up and down on the rams are attached to the cross girder G, to the underside of which is fastened the corrugating die $\mathrm{H}$; the bottom die $\mathrm{K}$ is secured to the bedplate $A$. The sheet $J$ to be corrugated is passed through the dies, and the pressure put on each time it is advanced; after the first corrugation, no guide is required, as the corrugations themselves perform that office. This machine by a very simple modification would form an effective plate-shears for ironworks, and designs by the writer for this purpose are under the consideration of some ironmasters who have expressed a favourable opinion respecting them. 
In the application of hydraulic power to machinery, however well it may be adapted for tools having a reciprocating motion, hydraulic motors have generally been considered not so suitable or applicable for driving machines with a rotary motion. But in Brotherhood's Three-Cylinder Hydraulic Engine, shown in Figs. 13 and 14, Plate 60 , all the objections hitherto met with in other attempts have now been successfully obviated. Three cylinders A, always open at their inner ends, are attached to a central chamber $B$, and a single crank-pin receives the pressure on the three pistons acting through the struts $\mathrm{C}$; the water is admitted and exhausted by means of the valve $V$, which is rotated by the eccentric pin $\mathbf{E}$; a face view of the valve is shown in Fig. 15. There being no dead centre, the engine will start in any position of the crank-pin, and a perfectly uniform motion of the shaft is obtained without using a flywheel. The pressure being always on the outer end of the pistons, the struts $\mathrm{C}$ are always in compression and take up their own wear. The power can be taken off from the engine either by a belt or by gearing, both plans being shown in the diagram; or, as in the case of a capstan, direct from the shaft. The writer's reason for referring to this engine is on account of its applicability to the extended use of water pressure for transmitting power to shop tools, becanse, owing to the great speed at which it can be ran, it will not only save the present loss from friction of gearing for transmission, but also reduce the friction in the machine itself by dispensing with gearing for getting up speed.

The application of hydraulic power to machinery has been carried out in a very complete manner by the writer at some extensive iron and corrugating works, the engineer of which, Mr. E. J. C. Welch, has enabled him to make a series of experiments for ascertaining the economical results of the use of hydraulic power as compared with steam power; and the writer takes this opportunity of acknowledging the value of his assistance. Previous to the adoption of the hydraulic corrugator and other hydraulic tools that have been described, these works were driven by a horizontal steam engine having a cylinder $18 \mathrm{in}$. diameter and $3 \mathrm{ft}$. stroke, which 
drove shafting through gearing in the nsual way. The corrngating was done by falling weights raised up by cams and let fall in guillotine fashion upon the sheets, causing much vibration and nuisance to neighbours, and involving the objection of the machine often breaking down. Two single-acting force pumps of 3 in. diameter and 12 in. stroke, attached to the engine, are employed to pump water into the accumulator, which has a ram $7 \mathrm{in}$. diameter and $12 \mathrm{ft}$. stroke, and was loaded in the first instance to $2300 \mathrm{lb}$. per sq. in. Pressure pipes lead from the accumulator to the various machines sitnated in different parts of the works, comprising a hydraulic punch and shears, two of the hydraulic corrugating presses, and a portable hydraulic riveter. A hydraulic crane is about to be erected near the corrugating presses to take away the sheets when corrugated; and a three-cylinder hydraulic engine is proposed to be put up for transmitting motion to shafting. The exhaust water passes through return pipes to the tank from which the pumps draw, and is used again.

With the object of obtaining some definite results in regard to the economy of hydraulic transmission of power as compared with steam, an extensive series of indicator diagrams were taken by the writer from the engine driving these works, and numerous experiments were made as to the power required for the punching and shearing machines \&c. The results obtained are however not so definite as was desired, in consequence of the great variations in the quality of the iron used in the trials, which caused conflicting results. It has consequently been determined to make a further series of experiments with the different sizes of iron of uniform quality.

As to the power saved by hydraulic transmission the following result was obtained. The indicated horse power of the engine at 50 rev. per min. was

6.65 Ind. H. P. when driving the transmitting shafting alone, 3.51 Ind. H.P. when running light without the shafting, leaving $3 \cdot 14$ Ind. $H$. $P$. as the power required for the transmitting shafting of about $300 \mathrm{ft}$. length. This shows that when running 
withont doing work 47 per cent. of the engine power was spent in transmission by the shafting; and a further loss has to be added for the friction of the gearing employed in getting up or reducing the speed of the several tools.

In the hydraulic transmission of power, on the contrary, the loss of usefal effect between the pumps and the accumulator is very little at the usual speed of working; for with one pump working, 1694 cub. in. was the theoretical delivery of the pump for 20 strokes, and $1614 \mathrm{cub}$. in. was the actual quantity pumped into the accumulator, showing a loss of only $4 \frac{3}{4}$ per cent.; and with both pumps working, the corresponding quantities for 20 strokes were 3388 and 3278 cub. in., showing a loss of only $3 \frac{1}{4}$ per cent. These experiments were carefully made, the accumulator registering the exact distance it travelled for a certain number of strokes of the pump.

The loss from friction in the accumulator was found to be as follows :-

$1250 \mathrm{lb}$. per sq. in. was the ascending pressure in the accumulator $1225 \mathrm{lb}$. per sq. in. " descending therefore, as in ascending the friction has to be overcome by the pump in addition to lifting the load, and in descending the friction has to be overcome by the load itself, the amount of the friction will be half the difference of pressure in the two cases, or $12 \frac{1}{2} \mathrm{lb}$. per sq. in., being only 1 per cent. of the power. This result applies equally to the friction in each of the hydraulic machines; and as the power is generally applied to the cutting tools direct from the ram, 2 per cent. represents all the loss from friction; and there remains only to add the loss due to the friction of the water in the pipes, which cannot amount to much if proper care is taken in proportioning their area and in avoiding bends.

In conclusion the writer wishes to express his obligations to Mr. James Platt of Gloucester, who, as the maker for him of. nearly all the special hydraulic machines described in the paper, has by his expenditure of labour, time, and skill, contribated greatly to the development of the system; and to Mr. Edward 
Wilson for first affording him an opportunity for applying the portable riveting plant to bridge work on a complete scale.

Mr. Twendel exhibited sectional specimens of riveting through several thicknesses of plate done by the hydraulic riveter, and planed down to the centre line of the rivets, showing the complete manner in which all the holes were filled by the rivets. He showed also a working model of the threecylinder hydraulic capstan engine.

Mr. D. Adamson considered they were much indebted to the author of the paper for the very complete way in which he had laid before them the particulars of the applications already made of hydraulic power; and there were many points referred to in the paper which he was sure would be found useful in various manufacturing operations. For his own part however he was not impressed with the importance of the application of hydraulic power to ordinary riveted structures; and as expressed at a former meeting he had an unfavourable opinion respecting the application of hydranlic power to riveting machines, on the ground that it necessarily involved the consumption of twelve or thirteen times as much power as would be used in doing the same work by a machine driven by rotary action through direct mechanical connections. For instance, in a hydraulic riveting machine having a stroke of 4 in., the work to be performed was all confined to the last $\frac{1}{4}$ in. of the stroke; and supposing the total pressure on the riveting die amounted to 25 tons, this large amount of force had to be exerted throughout the whole length of the stroke of 4 in., though producing a useful effect only during the last $\frac{1}{4}$ in. In the steelyard riveting machine that he had mentioned at the former meeting, not only was the whole of the 
power expended nsefully upon the work, bat at the same time the means was obtained of registering with exactness the force expended, and it was taken out of the power of the attendant working the machine to put a single pound more pressure or less pressure apon the work than the machine was adjusted for. Hence he considered this registering steelyard riveter could not be equalled by any other description of riveting machine either in the quality or in the economy of the work performed by it.

The subject of actuating workshop tools by hydraulic power had early been considered, he believed, at the works of Sir Wm. Armstrong, and it was found that in the case of a planing machine such a mode of driving would be very disadvantageous. The maximum force required in one part of the traverse might be $1000 \mathrm{lbs}$. pressure, and in another part only $100 \mathrm{lbs}$; and if in some parts of the traverse only one tenth the force was needed that was being constantly expended, it was a most extravagant expenditure, and such as he considered should never be permitted in mechanical operations of that sort. In respect of portability however and adaptability to shipbuilding and other special classes of work, the transmission of power by hydraulic pressure certainly appeared a very suitable arrangement. Also for dealing with the very thick plates now used in high-pressure marine boilers the hydraulic riveter was excellently suited; and in the case of riveting together a number of thicknesses of plate for bridge work, as in the sectional specimen exhibited, where the proportion of nseless expenditure of force in the earlier part of the stroke was less, and where it was necessary to compress the whole of the plates together by the high pressure of an accumulator, the hydraulic riveting machine might be advantageonsly used, becanse it would then be doing a larger amount of useful work than where the whole consisted in only forming the rivet itself in the concluding portion of a long stroke, as in riveting boilers and other ordinary riveted structures.

He had not had a large experience in other modes of producing rotary motion, but was decidedly in favour of shafting and simple leather belts; for whether it was an ordinary pulley in a machine 
shop or a belly-helve in a forge that had to be driven, the belt transmitted back to the engine the exact amount of resistance offered by the work executed, and there was then no loss by the expenditure of a needlessly large amount of power from an accumulator. In connection both with the employment of hydraulic pressure and with the steam hammer it appeared to him that engineers were a little liable to be too much taken up with one idea alone, and were consequently led sometimes into expending a great deal of power for little work done. For instance, the old-fashioned bellyhelve when lifted to its proper height would yield the maximum force from the power expended in lifting it; but with the steam hammer, in order to get a stroke of $4 \mathrm{ft}$. to hammer a shaft or ingot 12 in. diameter, steam had to be used the full length of the stroke while the blow was only equal to a $3 \mathrm{ft}$. fall; and hence a direet loss of 25 per cent. of power. No doubt a steam hammer was a very manageable tool, but it could not be called an economical machine in giving out force in proportion to the power expended to produce it. Similarly the system of hydranlic power might he thought be carried to an extreme, and was then apt to distract attention from the question of economy in working. On the other hand, for such operations as those described at the Paris meeting of the Institution in M. Tresca's elaborate paper on the "Flow of Solids" (Proceedings Inst. M. E. 1867 page 114), in which not only was lead forced through dies by hydraulic pressure, but even wrought iron when hot enough to be sufficiently plastic was subjected to identically the same treatment, hydraulic pressure was unquestionably a highly valuable agency, most appropriate for the work to be done and most economical in its action. There were many applications in which extreme force was required, where by no other mechanical means could the same work be done so efficiently, or probably so economically, as by hydraulic pressure.

The hydraulic flanging press described in the paper, which appeared a very practicable arrangement, was likely he thought to prove serviceable for flanging irregular forms, and also the internal flanges upon circular plates, where the metal had to undergo 
compression in forming the flange; but for regular forms, snch as cylindrical boiler flues or rings with external flanges, requiring the metal to be gradually elongated in the formation of the flange, his own experience was decidedly in farour of flanging in the ordinary manner by a machine having a rotary action; this he considered preferable to a hydraulic press, both on account of the greater expedition with which the work was done, and also in respect of economy of power. With a machine of this class in constant use at his own works a flange $3 \mathrm{in}$. deep was put upon a 7-16ths in. plate of $3 \mathrm{ft}$. diameter in from 25 to 30 seconds, the plate to be flanged being driven at 60 revolutions per minute. He should be happy to afford an opportunity at his works for a comparative trial of the rotary flanging machine employed there, so as to compare it with the hydraulic flanging press, in order to ascertain the rapidity with which the work conld be performed, and the power required as shown by indicator diagrams.

Mr. P. G. B. WESTMACOTT observed that in connection with the subject of hydraulic power there was a wide field for the exercise of ingenuity and skill; and he was sure they must all feel indebted to the author of the paper just read for the information he had given. With regard to hydraulic riveting, he remembered many years ago that a steam riveter which had been applied by Sir Wm. Armstrong at his works at Elswick had been successfully converted into a hydraulic riveter, and a very decided benefit had been found from the change. One great advantage of hydraulic riveting was that the pressure could be kept on the rivet and the plates held together until the rivet had got rather cool; consequently if there were any buckling in the plates this was prevented from acting on the rivet and disturbing it whilst it was capable of yielding. In an experiment that he had tried with the hydraulic riveter he had succeeded in completing a single-riveted boiler entirely steam-tight by the riveter alone, without touching it with a caulking tool; this was with $\frac{3}{4}$ in. rivets put in at an ordinary pitch. He had seen one of the portable hydraulic riveting machines described in the paper at work on a bridge in London, and had 
been so much impressed with its value that he had ordered one for application in a somewhat modified form in the construction of a large swing bridge now making over the river Tyne.

In reference to the remarks just made respecting loss of power in certain applications of hydraulic power, he quite agreed that it would be very inexpedient to employ hydraulic machines for all kinds of mechanical operations; and he considered it was only for particular applications that hydraulic power was suitable. At the same time it was necessary to take into account the loss of power continuously going on in driving the shafting and gearing of machines not worked by hydraulic pressure. In a trial that he had made upon a length of $1200 \mathrm{ft}$. of shafting averaging $2 \frac{3}{4}$ in. diameter, which had been running for some years, he had found that, when the driving belts were all thrown off, the power required to drive the shafting alone at a speed of 120 rev. per min. amounted to as much as 1 Ind. H. P. for every $100 \mathrm{ft}$. length of shafting. This loss was going on continuously, whether the whole of the machinery was being driven by the shafting or not; and in addition there would be the further loss from the friction of the belts and gearing of the various machines driven. In many cases therefore where machines acted intermittently, instead of running continuously, it seemed to him probable that a hydraulic machine would not only be better adapted for the work to be done, but would also entail less loss of power than a machine driven by shafting.

The hydraulic flanging machine described in the paper afforded certainly a very quick and efficient means of performing the operation of flanging plates; but he had not himself experienced any of the difficulties alluded to in this class of work, and with a simple machine which was constantly used for the purpose at the Elswick Works he had not found any difficulty in bending plates even to as sharp curves as those shown in the drawing.

In reference to the employment of the intensifying accumulator described in the paper, for avoiding the necessity of carrying across country the heary weights required with an ordinary accumulator, he enquired whether an air vessel had ever been 
applied for working a portable hydraulic riveter. In special cases of that kind he thought an air vessel would be adapted for isolated situations; in the experience he had had of air vessels working under high pressure he had found no difficulty in their application. At the present time he had air vessels working at a pressure of $850 \mathrm{lb}$. per sq. in., and supplying a large plant of hydraulic machinery in situations where it had not been found expedient to introduce an accumulator on account of its weight or size.

In the three-cylinder hydraulic engine shown in the drawings he enquired whether the revolving disc-valve was found to work satisfactorily, in the absence of any relief valve for preventing shock from the water at the end of each stroke. Unless the exhaust port in the valve were made long enough to give a little lead, so as to afford a prompt and free exhaust from the cylinders, the valve would be liable to be lifted from its face by the shock of the exhaust water; the lifting of the valve would be objectionable, because any particles of grit in the water would then be apt to get onder the valve face and gutter it. He also questioned whether the balancing arrangement wonld be found efficient in practice.

Mr. H. Chapman observed that, with regard to the pressure employed in the hydraulic riveter, this was not necessarily the same throughout the entire stroke; and it had been mentioned in the paper that by taking advantage of the impulse of the falling accumulator at the end of the stroke a dead pressure of 40 tons was increased to nearly 60 tons at the time of closing the rivet; the machine thus starting with the lower pressure arrived at the higher pressure at the point at which it was required. He had seen a great deal of the hydraulic riveting, and the work was in all cases nnexceptionable. At the works of Messrs. Penn, in places where the tapered corners of three thick plates had to be riveted together in marine boiler work, the bydraulic riveters were very conveniently employed; having the riveting dies replaced by dummy dies, these were applied to bring the plates together and hold them so, the plates having been previously warmed by the application of hot

E 2 
iron blocks. The pressure from the riveter was kept against them until the plates were cold; the dummies were then replaced by dies, and the riveting done, which was perfectly steam-tight at $150 \mathrm{lb}$. per sq. in. pressure.

It had been mentioned that there were now upwards of a hundred of these bydraulic riveters in use ; and he should be glad to hear the experience of some of those who had used them. His own experience of the hydraulic riveters had been so satisfactory that he should certainly have them employed npon all boiler and bridge work with which he might be connected. He enquired whether the cost had been ascertained of putting in a number of rivets by the hydraulic riveter, as compared with the cost of putting in the same number by steam riveting and by hand.

The pressure in the ordinary construction of accumulator being got by weights, he asked whether any attempt had ever been made to reduce the weights, so as to do smaller riveting with a corresponding pressure. As it was impracticable in small shops to have a separate riveting machine for every different thickness of plates to be riveted, he suggested that some such plan would be applicable for that purpose, so as to get a lower pressure for lighter descriptions of work; and it seemed to him a simple matter to arrange.

The question of packing was a point of vital importance in hydraulic machinery, and hemp having been stated by the author of the paper to be pretty generally used by himself, he should be glad to know why it was preferred; and whether leather or metallic or hemp packing was best for a moving piston or for a stationary stuffing-box. Also whether a different packing was required for high and for low pressures, and for different speeds of working.

The hydraulic capstan worked by Brotherhood's three-cylinder engine he had several times seen in regular work in London at the Broad Street goods station of the London and North Western Railway; and on one occasion when it was desired to see the state of the valve, the machine was taken entirely to pieces and put to work again in only 17 minutes, which showed the simplicity of the construction of the machine and the facility 
for getting at the valve; this was found to be in perfect condition. If therefore the valve should be found at any time to be worn, it could easily be replaced; and it was not an expensive part to have in duplicate. He enquired what material had been found the best for the valve: whether it was a brass valve working on a cast-iron face, or cast-iron on cast-iron.

Mr. P. Brotherhood replied that hard phosphor-bronze was used for the valve of the hydraulic capstan, and also for the crank-pin bearings. By means of the arrangement of the balance ring at the back of the valve, the area of unbalanced pressure and the consequent pressure per sq. in. on the working face of the valve could be varied as desired; and in the earlier capstans the proportion of the balance ring had been such as to give a pressure of $900 \mathrm{lb}$. per sq. in. on the working face of the valve; but subsequently the diameter of the balance ring had been increased, and owing to the diminished unbalanced area on the back of the valve the pressure on its working face was thus reduced to $300 \mathrm{lb}$. per sq. in., under which the valves were found to wear extremely well. It had been found quite unnecessary to provide any relief valve; the length of the exhaust port in the valve was made exactly the same as that of the port in the cylinder face, and there was not found to be any shock whatever from the water in the working of the machine.

The question of packing, which had been alluded to, was one of great importance. In the hydraulic capstans be had used at first deep cupped-leathers for the packing of the pistons and valves, like those shown in the drawing, Fig. 16, Plate 61, but these did not run satisfactorily; he then had bucket leathers made, of shallower section so as to be stiffer in the lip, as shown in Fig. 17, and with the flesh side of the hide outwards; these stood the hardest work at the Broad Street station, where they had already been in use for five months, and others were in use elsewhere, with equal success.

A metallic packing that he had used in other cases with some success consisted of a gunmetal ring I, Fig. 18, which was slit and 
tongued in the usual way to allow the requisite elasticity, and for the packing of plungers it was surrounded ontside by a continuous india-rubber ring of $U$ section; the flanges of this india-rubber ring were forced outwards and formed a tight joint in the groove in which it lay in the gland, when the water pressure came upon the back of it, and the metallic ring was thus kept compressed upon the plunger. For pistons the reverse arrangement was adopted, as shown in Fig. 19, the india-rubber ring being placed inside the metallic ring, so that the water pressure coming behind it kept the metallic ring pressed outwards against the sides of the cylinder; in double-acting pistons the water pressure was admitted into the interior of the piston through small holes drilled in each face round the circumference and covered by the lips of the india-rubber ring, so that in the upstroke the pressure entered the piston through the holes in the lower face and closed those in the upper face, and the converse in the downstroke, thus preventing leakage through the piston. This construction of metallic packing was only good for clear water; it was apt to cut in dirty water.

The President enquired whether there was any motion upon the india-rabber ring in that arrangement of packing; and whether there was not considerable friction, as it appeared the moving surfaces were under the full pressure of the water acting on the back of the packing.

Mr. P. BROTHERHOOD replied that the friction was considerable on that account; but he used this packing to a great extent and found it very convenient, because it had the advantage of being self-acting and requiring no attention. The india-rubber ring lay passive without any motion, the metallic ring being held endways in a groove in the gland or piston.

The cast-iron connecting-rods or struts for the three cylinders of the hydraulic capstan were made in a very simple manner by casting the three together in one piece, boring them for the crank pin, and then breaking them apart, after which the ends only required rounding with a file, without any expensive fitting. 
Mr. J. RAMsвoтtom observed that many ingenions arrangements of hydraulic machinery were described in the interesting and suggestive paper now read, and there were several points in it which might be attended to with great profit, especially in respect to the economical use of fuel. For certain classes of work he agreed with the opinion which had been expressed that there was a great loss of power in the use of hydraulic pressure as compared with ordinary shafting; where shafting could be continuously employed for driving shop tools, it must necessarily be preferred to hydranlic power. But the case was reversed where the power was required to be ased at variable intervals of time and at a distance from the prime mover ; and hydraulic arrangements might then be employed with great advantage. For such tools as planing or slotting machines however he did not think hydraulic power could be either theoretically or practically advantageous, on account of the varying resistance encountered by the tool at different points in the same cut; there were places where the resistance might be nearly equal to the full force of the hydraulic pressure, and others where it might be not more than one tenth as much, whilst the power would continue uniform, being supplied by the constant pressure of the accumulator. Thus the velocity of the cut would vary greatly in different parts of the work, instead of being kept uniform at the one proper speed required for the particular material operated upon. This difficulty of reducing the pressure so as to meet the work to be done would attend any application of hydraulic power for driving a shop containing a number of machines working simultaneously, since the tools would require some of them the full pressure and others less, while the accumulator would have to be kept always at the full maximum pressure. The conclusion he came to therefore was that there was much to be said on both sides as regarded the mode of driving by rotating shafts or by bydraulic power. The practical success of the hydraulic system as applied to cases where large amounts of force were required to be exerted at remote distances from the prime mover was abundantly evident from the experience of Sir Wm. Armstrong's arrangements in this branch of mechanical engineering; and if the system had not 
been radically sound in these applications, it could not have continued so successful to the present time. It was possible however to push any good idea too far, and by looking too exclusively in one direction to get misled and to make misapplications of a sound principle.

The three-cylinder hydraulic engine was a very ingenious machine; and he did not see that there could be any practical objection on account of shock from the water, owing to the vature of the valve employed, which was not reciprocating, but rotated with great velocity, especially in relation to the velocity of the piston at the moment when the port was being opened. Any relief required beyond that afforded by the valve would be met by the small quantity of air which water ordinarily contained, and by the elasticity of the working parts \&c. Even if there had been any shock, he did not consider it would have been found to occasion any practical difficulty, as none of the working parts would be forced out of place by it.

Mr. E. A. COWPER remarked that the use of hydraulio power was a subject which had engaged his attention for many years; and he remembered long ago, before the accumulator was invented, hearing of a range of hydraulic presses at a paper mill, one of which was loaded with pig iron and served as a reservoir of power for working the other presses; when any one of these presses was required to be brought into action, a valve was turned and the press was run up by running this reservoir down. Subsequently at Messrs. Fox and Henderson's works twenty-seven years ago he had applied hydraulic presses for working iron, and had a hydraulic reservoir having a large ram at top and a small one below, to which the weight was hung for working the presses. One of the operations performed by this means consisted in cutting out the links for suspension bridges, with the oval end and slot end for adjustment $1 \mathrm{ft}$. $4 \mathrm{in}$. across; each link was $7 \frac{1}{2} \mathrm{ft}$. long, 10 in. wide in the body, and 1 in. thick, and was cut complete out of the solid hot plate in a press having two 9 in. rams; the process was quite satisfactory and a most convenient mode of 
working. With the packing leathers he had had no trouble, inasmuch as they were good leathers, nicely applied in the first instance. These machines gave no trouble, and their use was extended to many different operations, including the shaping of large quantities of spokes, cutting out axleguards, and a variety of forgings and weldings. In connection with this subject of dealing with iron by pressure, instead of by blows, he might mention that the plan of welding tyres with a butt joint was introduced at that time, by bringing the ends together while they were in the fire by means of a screw clamp, the welding being thus completed very effectively without any hammering.

With a heavily loaded accumulator of relatively small eapacity it had been mentioned that a much heavier pressure was obtained at the end of the fall, giving something of the effect of a blow upon the work; and thus although the falling weight might not be doing its full work in the earlier part of its fall, the effect of the fall was not altogether lost, but was transformed into an increased final pressure. For general nse however he should prefer a steady pressure from the accumulator, without anything of a blow from the momentum of the descending weight.

With regard to the circular disc-valve of the hydraulic capstan, he did not consider there was any necessity to provide a relief valve for preventing shock from the water; he had not employed a relief valve in any hydraulic machines, and had not found it necessary to do so. It was only requisite that a slide-valve should remain open to the exhaust until the moment when the piston arrived at the extreme end of its stroke, and the port could be reduced in size by notching it or making it diagonal; and as the valve was at that time moving with its greatest velocity, while the piston was just starting from a state of rest, the valve opened the admission port quicker than the piston could take the water; and for the same reason an ample exhanst opening was maintained until the very end of the stroke, thereby preventing the occurrence of any shock from the water.

The plan introduced by Mr. Webb of using oval rivets in special situations seemed a very good one, provided care were 
always taken to put the rivets in the proper direction, edgeways to the strain; and he wished to know what increase of strength was found to be obtained by that plan, or what percentage of saving in the number of rivets required.

Mr. J. Platr, alluding to the alleged great loss of power in the hydraulic riveting machine in consequence of its utilising only about one twelfth of the whole power expended, whilst in a rotary machine all the power was utilised, observed that he differed altogether from that statement of the case; the rotary machine he supposed required rather a heary flywheel for the purpose of storing up the power for use at the moment it was wanted, and considerable power would be absorbed in keeping ap the momentum of that wheel, which had to be kept in motion whether the rivets were being closed or not. With regard to the steelyard arrangement for adjusting the closing pressure according to the size of the rivet, the same provision was made in the hydraulic riveter by adjusting the weight upon the accumulator, and the full accumulator pressure was exerted upon every rivet. For obtaining the advantage of the momentum of a falling weight, the area of the accumulator ram was so proportioned as to give a fall of 12 in. for putting in each rivet; and it was then found that the momentum of the falling weight gave the advantage of an increase of 25 per cent. in the closing pressure upon the rivet, above the pressure to which the accumulator was loaded. In working with an accumulator not so proportioned as to give this advantage of momentum, there was no doubt considerable loss of power in moving the riveting die through some four-fifths of its stroke under the full pressure before it touched the rivet; and it would be quite practicable to obviate this by using a lower pressure from a separate source during the first part of the stroke. But in ordinary practice what was wanted was to reduce the riveter to as simple a machine as possible, in which there was consequently less leakage, though some sacrifice of power.

The hydraulic flanging press described in the paper he had seen at work in Prussia, and it did its work very well. The parabolic 
curve given to the matrix turned the edges of the plate in very gradually all round, and as true as could possibly be required; the advantage over a square die was not only that the flange was bent more gradually by the curved matrix, but also that in consequence of the matrix being made in the form of an open ring, there was no difficulty in getting the finished plate off the block, as the open matrix left it free to drop off the block immediately upon the completion of the flanging.

Mr. P. R. JACKsON mentioned that some years ago, having to construct a hydraulic press cylinder of extra size and strength, he had designed a method of avoiding the unsoundness to which large thick cast hydraulic cylinders were liable, by employing a very thin shell or cylinder cast of close and rather hard iron, which might be lined or not with copper or brass, rendering it very water-tight under heary pressures; this thin shell was hooped with wrought iron or steel, sometimes two or three sets of hoops being placed one over another to give the requisite strength. One press which he made forty years ago on that plan was over 21 in. diameter, and was still at work. That method of constructing hydraulic cylinders was at the time considered a great step in advance; now small cylinders could be cast of steel, but for large sizes it was still found advisable to hoop them with steel or wrought iron. The method of driving machinery by hydraulic power he considered an expensive one, and it could only be profitably employed in exceptional cases. He thought the information given in the paper was valuable, and there was a great deal to be learnt from it.

Mr. D. GREIG observed that for a portable riveter there was of course a considerable advantage in using a high pressure of water, so as to reduce the machine to a convenient size that could be easily carried about. But for a stationary riveting machine in a shop a lower pressure would have to be employed, such as it would be practicable to carry all over the shop; and he enquired whether the larger size of ram then requisite for working the riveter with this lower pressure would be attended with any disadvantages. 
In the flanging machine described in the paper, he did not see any advantage in the open ring die shown in the drawing, as compared with an ordinary solid die, provided the edges of the die were made of the same curved form in each case. He had found very little difficulty in flanging plates by pressure with solid dies, or in getting them off the block again after flanging.

The use of leathers for the packing of the hydraulic riveting machines had in his own experience been attended with some trouble and expense; he had found hemp packing the best for the purpose, and now used it in all hydraulic machinery he had at work.

Mr. Banjamin Walker referred to the statement made in the paper, that in the experiment tried for ascertaining the friction of shafting this had been found to amount to as mach as 47 per cent. of the whole power of the engine when running without doing any work; and he enquired what percentage that would be of the gross power ordinarily exerted by the engine when doing work. He mentioned that sixteen years ago, in connection with machinery for driving the extensive flax mills of Messrs. Marshall in Leeds, where there were thousands of belts and loose palleys, he had taken the opportunity of ascertaining by experiment the exact amount of power absorbed by the friction of the shafting, and had found that it took less than $2 \mathrm{lb}$. per sq. in. pressure on the piston to drive the shafting and belts alone, the mean pressure being about $20 \mathrm{lb}$. per sq. in. when the engine was driving the machinery in ordinary work; the engine was a new one, and the boiler was worked at a pressure of $40 \mathrm{lb}$. The friction of the shafting was thus less than 10 per cent. of the whole power of the engine in ordinary work. On trying the same experiment at Mr. Gott's woollen mill in Leeds, where there was a common wagon boiler working at only $5 \mathrm{lb}$. pressure, the result was found to be about the same percentage.

While fally concurring in the remarks that had been made as to the considerations limiting the applicability of hydraulic pressure, he hoped the writer of the paper would persevere in his endeavours to extend the applications of that power, and that others also would make trials of it; any defects in the system 
wonld thns be brought to light, remedies would be suggested, and the experience so gained conld not fail to be profitable.

Reference having been made to the use of the old-fashioned belly-helve in comparison with the modern steam hammer, he remembered many years ago, at some ironworks then newly erected, the prejudice that existed in favour of the old belly-helve was so strong as to lead to the complete exclusion of steam hammers at the starting of the works; it was even believed to be impossible to make good iron without a belly-helve. Subsequently however a steam hammer was admitted, and afterwards others were added, until nltimately the belly-helves were altogether abandoned; it was found that equally good iron was made under the steam hammer, and also the iron could be more easily worked by this means, and less skill was required. The practical reason of its superiority was that the work could be so much more easily dealt with than under the old helve.

With regard to the intensifying accumulator described in the paper, he mentioned that there were in Leeds a number of woollen warehouses in which a great many hydraulic presses were employed for packing the goods; and in order to do away with the labour of pumping these presses up by hand, as had previously been the case, he had introduced a contrivance for using the waterworks pressure of about 40 to $70 \mathrm{lb}$. per sq. in. to give a pressure of as much as $2,500 \mathrm{lb}$. per sq. in. The town pressure was admitted into a cylinder having a ram of $14 \mathrm{in}$. diameter and $3 \mathrm{ft}$. stroke, which acted upon another ram of only $1 \frac{5}{8}$ in. diameter, this difference of area giving the required increase of pressure. The bigher pressure was admitted to any of the hydraulic presses by simply turning a tap, and the result was very satisfactory in the facility of working the presses without hand labour.

Mr. J. Riohardson said that at Messrs. Robey's works at Lincoln he had had a couple of the hydraulic riveters in use for two years, driven by one accumulator, and had found the economy was very considerable in comparison with hand labour; the work was done at not more than one third of the cost of hand riveting, and what 
was of much more importance it was found to be much sounder done, as there was no temptation to overheat the rivets; it was a rare thing to have one broken, and the amount of caulking required was very slight indeed. He had not had the means of making a comparison with steam riveting; but before purchasing the hydraulic machines he had examined several steam riveters, and was convinced the hydraulic plan was preferable.

For obtaining the effect of a blow from the momentum of the falling weight in the accumulator, the size of the accumulator and the length of stroke of the riveting dies were so arranged as to get 18 in. fall of the weight for each rivet, thus giving a much greater terminal pressure upon the rivet head than was obtained in any other part of the stroke; and he considered it preferable to use a comparatively light weight with considerable fall, so as to get a lower dead pressure in the early portion of the stroke of the riveting die, and a heavier blow in closing the rivet.

With respect to the use of leather or hemp or metallic packing for hydraulic machines, he had had considerable trouble at first with the ordinary cupped-leathers fitted in the accumulator working the hydraulic riveters, on account of having to use water that was impregnated with lime and sand. The leathers were found to get cut away very quickly indeed, seldom lasting more than two days, while sometimes two leathers a day were used, and it was very well if a leather ever lasted so long as a week. Hemp packing was then recommended by the makers of the machinery; and in other instances in which he had used hemp packing for hydraulic machives he had found less trouble and better results with it than with leather. But before taking the trouble to change the cuppedJeather in the accumulator for hemp packing, he had determined to try some means of preventing the excessive wear of the leathers, which was attributed to the dirty water getting in between the leather and the ram, as it was noticed that a slight leakage took place just when the accumulator started to lift and when consequently the pressure had just been off the leather. The accumulator being emplojed for the riveters alone, and being charged by a pair of force pumps which were kept constantly at 
work, had been at first so arranged that on reaching the top of its stroke it closed the suction valve of the pumps; these continuing to work became partially charged with air, and when the riveter started working, about four rivets brought the accumulator down on the bottom stops, often before the pumps had got so far rid of the air as to start lifting the accumulator again. When thus resting on the stops, all pressure was of course taken off the leather of the accumulator ram, and it was just when the accumulator started to lift again that the leakage took place; and this occurred many times in a day. If the water could be prevented from thus getting between the leather and the ram, it was hoped the leather packing could continue to be used, as it was the simplest and most convenient kind of packing for the accumulator. Wedge-shaped india-rubber bands were first tried, slipped over the inner flange of the cupped-leather so as to keep it always pressed against the ram all round; and the leather was then found to wear twice as long. Afterwards hemp was wedged into the annular groove of the capped-leather, so as to press it still tighter on the ram, and the leathers were thereby made to wear still longer. The expedient ultimately adopted was to put a relief valve on the delivery pipe between the pumps and the accumulator, and to leave the suction valve always open, the relief valve lifting whenever the accumulator ram reached the top of its stroke; the pumps being then always charged with water, the accumulator was never able to get down to the stops at bottom, and consequently the pressure was never taken off the leather. The mischief having previously been done by the sand getting in between the leather and the ram, this plan of maintaining a constant pressure upon the leather proved a complete remedy; and he thought if it had been tried in other cases, instead of having recourse to metallic or hemp packing, the use of leather might have been continued. Instead of the leathers in the accumulator lasting only two days, he had now had them last as long as sixteen weeks; but for security they were changed regularly every three months, and he never had any trouble now from the leathers giving way. The ram of the accumulator in which the leathers were working was cased with gunmetal. 
Mr. E. A. Cowper enquired whether there was any iron in the water. That always injured leathers very quickly, because it combined with the tannic acid in the leather, and formed ink.

Mr. J. Richardson believed the water must contain iron, because it was found to make the leathers black and hard. This was not of much consequence however, as it did not prevent them from lasting in the accumulator sixteen weeks or upwards, which was long enough to be quite satisfactory. The leathers on the rams of the riveters lasted from eighteen to twenty months, the motion and consequent wear in that case being extremely limited. The same water was nsed over and over again, so as to avoid bringing in any more sand than that introduced at the ontset; there was of course a slight leakage, which had to be made up, but it was very small indeed.

Mr. D. CampBetL, referring to the use of leathers for packing and the means of keeping them tight with little friction, mentioned that in some hydranlic presses for expressing oil, with which he had had to do in India many years ago, and more recently in some presses for packing cotton, oil had been used instead of water, and when the cast-iron rams began to get worn they were cased with gunmetal to prevent them from tearing the leathers; by this means the leathers had been made to last as much as two years, and at the same time the friction was considerably reduced. In these presses however, as it was only through a comparatively short length at the end of the stroke that the heavy pressure and consequent wear upon the rams took place, the gunmetal casing was not required to extend more than a short length, about $2 \mathrm{ft}$. in the cotton presses, forming a shoe or thimble upon the end of the ram. For rams of 11 to 13 in. diameter the gunmetal shoe was made about 1 in. thick.

Mr. T. WRIGHTSON referred to the very interesting experiment named in the paper for ascertaining by means of a pressure gaugo the friction in the gland of the accumulator, the gauge indicating a 
pressure of $1250 \mathrm{lb}$. per sq. in. when the ram was ascending, and $1225 \mathrm{lb}$. during its descent; and he enquired what was the diameter of the ram in that case, and the kind of packing used, and also whether the velocity of the ram in descending was the same as in rising. These were all three very important elements in the experiment.

Mr. TWEDDELE replied respecting the comparative efficiency of the hydraulic flanging press described in the paper and the rotary flanging machine which had been referred to, that the hydraulic press was admitted to be the best for irregular shapes; and for ordinary flanging also he considered it would be found the most advantageons, becanse with a rotary machine he understood the flange was liable to be made sometimes of irregular thickness. The advantago of the hydraulic press was indeed more especially seen in the flanging of irregular shapes, such as the front plate of a locomotive firebox, which required to be flanged in opposite directions; this could be completed in the hydraulic machine at two operations, the first forming the circular flange for attacbment to the shell of the boiler, and the second then forming the ontside flange for riveting to the top and side plates of the firebox. He should gladly avail himself of the opportunity that had been offered for making a practical comparison of the two machines. The object of the inverted form of the press, and of the open ring die or matrix instead of the ordinary form of solid die, was to allow the plate to fall off the block by its own weight and drop throngh the open die immediately upon the completion of the flanging, before it conld have time to contract on the block in cooling. In the ordinary mode of flanging a plate, by placing it on the top of the block, he had always found the contraction caused a difficulty in getting it off the block again; and in the case of flanging some plates in Germany for portable engines be had seen the method tried of constructing the block in segments, with a central cone or wedge which was taken out as soon as the flanging was completed, so as to let the block contract and leave the plate free; bat he considered the arrangement of the hydraulic flanging press was decidedly saperior. 
In reference to the statement made that with the hydraulic riveter a boiler had been completed steam-tight without canlking, he had himself also riveted by that means several portable boileps in Germany, with $\frac{3}{8}$ in. plates and $\frac{5}{8}$ in. rivets, which were never caulked, but were perfectly steam-tight and proved in every respect satisfactory.

In addition to the remarks already made respecting the loss of power attending the application of water pressure in place of shafting for driving machinery, it must be taken into consideration that the pressure pipes which took the place of the revolving shafting were fixed and stationary, entailing no expense for repairs, while all shafting was constantly wearing itself away by friction. As regarded the amount of power required to drive shafting, the result obtained in the trial mentioned by $\mathrm{Mr}$. Westmacott, namely about 1 Ind. H. P. per $100 \mathrm{ft}$. length of shafting, was about the same as at the Liverpool works referred to in the paper, where the length of shafting driven by the engine was about $300 \mathrm{ft}$. and was found to absorb $3 \cdot 14$ Ind. H. P.

In applying the portable hydraulic riveter to the swing bridge now in process of construction over the river Tyne, it was proposed by Mr. Westmacott that the main accumulator, situated inside the central pier for moving the bridge itself, should be employed for working the riveter, the pressure in the main accumulator of only $700 \mathrm{lb}$. per sq. in. being raised by means of an intensifying accumalator to the pressure of $1500 \mathrm{lb}$. per sq. in. required for working the portable riveter.

The suggestion of substituting an air vessel in place of a dead-weight accumulator was one that had occurred also to himself; but he bad not yet carried it out. The plan had however been used for many years by Messrs. Tangye of Birmingham, for small portable bydraulic stamping and forging presses.

In reply to the enquiry about the comparative cost of riveting by the portable hydraulic riveter, he was informed that the average cost of putting in $1 \frac{1}{4}$ or $1 \frac{3}{8}$ in. rivets through $1 \frac{1}{8}$ in. plates by this means was found to be from $38.6 d$. to $4 s .6 d$. per hundred, including the wages of the man working the riveter and also of the 
men at the cranes for shifting the work; and this was the general experience in a large number of cases where the hydraulic riveter had now come into regular use. By hand labour the same work could not be done for less than 27s. or 30s, in the North of England. At some large agricultural engine works $\frac{5}{8}$ in. rivets were being put in at $1 s$. to $2 s$. per hundred by the hydranlic riveter; and this he believed was the lowest cost at which such work could be done. In comparison with steam riveting the saving with the hydraalic riveter was not so great, but was still very large; the riveting of thick plates or of several thicknesses of plate could not be done at all satisfactorily by a steam riveter, but only by hydraulic power. The manufacture of the portable hydraulic riveter had been entrusted to Messrs. Fielding and Platt of Gloucester, whose sole aim had been to perfect the machine to the utmost; and he was glad to take this opportunity of stating how very much he owed to Mr. Platt's assistance throaghout. The hydraulic riveting plant that had been employed upon the Primrose Street railway girder in London had since been purchased by Messrs. Cail of Paris; and similar plant had been sent out to other places, where it was now coming into general use. The employment of oval rivets had been suggested by Mr. Webb, but they bad at present only been used for some locomotive fireboxes made of steel at Bolton; in that instance the saving effected in thickness of plate by their nse was stated to be 20 per cent., but the percentage of saving would of course depend upon the proportions of the oval section.

As regarded packing, he had worked the hydraulic riveters with pressures of 1500 to $2000 \mathrm{lb}$. per sq. in. with leather packings, and he agreed in preferring gunmetal for the leathers to work upon, wherever the greater expense was not objected to, as he believed the friction of the leather upon gunmetal was rather less than upon iron, but of this he was not certain. A preference had been expressed for metallic packing, provided perfect cleanliness could be ensured; but this was based he presumed upon the experience of metallic packing used in steam engines, and it must be borne in mind that the average pressure in a steam cylinder 
was probably seldom above 40 or $50 \mathrm{lb}$. per sq. in.; whereas with water, where any of the great pressures were used, he did not believe metallic packing was of any use at all. From this consideration he had never used any metallic packing for hydraulic machines. He was glad to hear the information given about the hydraulic riveters at Messrs. Robey's, which had been at work there a considerable time; and the effects which had been mentioned of dirty water upon leather packing were confirmed by his own experience. In the hydraulic punching and shearing machine shown in the drawing, trials had been made of cupped-leathers, vulcanised india-rubber, and hemp packings; and he had come to the conclusion that hemp was the most suitable packing for hydraulic machines, except where gunmetal could be used for all the wearing surfaces, and then the question of expense came to be considered. The question was not simply one of greatest durability, but also of facility of renewal; in order to replace a leather packing it was necessary to take the machine to pieces sufficiently for getting the ram out, and then to slip the leather ring over the end of the ram and up into its place. Bat with hemp packing it was only requisite to take the gland off and put the hemp into the stuffing-box, which caused a great saving in time and expense. $\mathrm{H}_{\theta}$ had found the hemp or flax packing answered every purpose, and had consequently adopted it and was now using it in every case.

The packing in the accumulator at the works in Liverpool, where the experiment named in the paper had been tried, was of hemp, and the result arrived at as to the friction was almost identical with those obtained in Mr. Hick's experiments on the friction of cupped-leathers, which the experience of the working of hydraulic machinery had shown to be quite correct; and corresponding results had also been obtained from accumulators by Sir Wm. Armstrong. In the experiment at the works in Liverpool the ram of the accumulator was $7 \mathrm{in}$. diameter with $12 \mathrm{ft}$. length of stroke, and the velocity in ascending was just about the same as in descending, the feed pumps having rams 3 in. diameter and 12 in. stroke. 
For the slide-valves and mitre-valves of hydraulic machinery he was now occasionally using the hard phosphor-bronze, and this was found very durable for the purpose, although a good mixture of gunmetal proved very satisfactory.

In reference to the relative advantage of using a moderate pressure with a large ram in hydraulic machines, or a high pressure with a small diameter, it must be borne in mind that the friction of the water was not perceptibly increased with the increase of pressure, and consequently there was no loss in using the higher pressure, which allowed of a more compact machine; and practical experience had shown that there was no trouble in keeping the pipe joints tight at pressures of 1500 or $2000 \mathrm{lb}$. per sq. in. At the same time he did not think there was any occasion for carrying such high pressures throughout the whole of a works, and a much lower pressure would be sufficient for working the foundry cranes and other cranes; in such cases there was certainly a limit to the extension of a high pressure. At Sir Wm. Armstrong's works at Elswick the hydraulic machinery was all arranged he believed for a pressure of $700 \mathrm{lb}$. per sq. in. throughout the works, with the exception of a riveting machine, which had been converted from a steam riveter, and was consequently worked with a lower pressure corresponding with that which had been used when steam was employed. But in some steam riveters that had latterly been converted by himself he had substituted a small hydraulic cylinder for working with a pressure of $1500 \mathrm{lb}$. per sq. in. Over and above the dead pressure of the accumulator however, he considered there was great value, for the working of riveting machines, in the impulse derived from the momentum of the falling weight, by making the accumulator ram in this case sufficiently small in diameter, so as to cause a considerable drop of from $18 \mathrm{in.}$ to $24 \mathrm{in}$. for each rivet; the dead pressure of 40 tons on the rivet was thus raised to a closing pressure of as much as 60 tons, coming upon the rivet with the effect of a blow, after which the dead pressure of 40 tons still continued upon the rivet, and kept the plates pressed tight together until the rivet was cool; by this means three thicknesses of plate in boiler work were riveted perfectly steam. 
tight at once, without any caulking. The adjustment of the pressure for lighter descriptions of work was readily effected by simply relieving the accumulator ram of a portion of its load, by stopping some of the upper rows of weight-segments by means of a suitable catch. With respect to the loss of power occasioned by employing the same high pressure through the whole of the stroke in a riveting machine, this was a question of expediency which superseded the question of pure economy; and he certainly did not consider it worth while, in the present case of the hydraulic riveter, to complicate the construction by any arrangement for compounding a high and a low pressure of water, although he had designed several arrangements which would meet the case.

The friction of the shafting in the experiment deseribed in the paper had only been ascertained in relation to the power of the engine when running without doing work; but he would endeavour to ascertain the percentage it bore to the engine power exerted in ordinary full work, so as to add that information to the paper.* The machinery in a flax mill however, such as had been referred to in the discussion, was very different from that in a boiler yard or engineering works, and there was a considerable difference in the working of shafting in the two cases. He had heard of shafting several hundred feet long so well put up that it could be turned round by hand; but he had never met with anything like that in a boiler yard or macbine works.

The utilisation of a moderate waterworks pressure in towns for driving hydraulic machinery, in conjunction with an intensifying accumulator, was a most important question. 'In Newcastle-on-Tyne the available town pressure on the quays was about $80 \mathrm{lb}$. per sq. in., and this was very extensively applied direct from the main to a variety of purposes; a printing engine in another part of the town had also been driven by the same means for many years past. The three-cylinder hydraulic engine described in the paper would be very applicable for all rotary work, and small engines of that kind would render the employment of the town pressure much

* This percentage has since been ascertained to be about 15 to 17 per cent. of the engine power exerted in ordinary full work. 
more practicable than hitherto; he hoped the plan would soon come into extensive use.

In the remarks which had been made respecting the limits to the application of hydraulic power he fully concurred, believing water pressure to be in most cases unsuited for such operations as planing or slotting, although many of the objections urged would be diminished if the system were completely carried out; and he was glad that opinions as to its proper limits had been so clearly expressed. To advocate an indiscriminate use of hydraulic power for all purposes he considered a mistake; and while he was guided by the example of Sir Wm. Armstrong's practice to a great extent, he did not see any limit to adapting similar principles to other cognate applications with equal success.

The Prestoent, referring to the mention which had been made of the use of the hydraulic riveters at Messrs. Penn's works for riveting together three thicknesses of heavy plates in marine boilers, said he had no doubt every engineer would prefer to have heavy platés and boilers riveted by a power machine instead of by hand; indeed the present large marine boilers could not be riveted at all by hand labour. The use of powerful riveting machines with proper management prevented bad work in the manufacture of boilers; but of course in the hands of a careless workman they would not be so successful. When the plates were not properly closed before the riveting was done, a collar was formed on the rivet between the plates, and when once this was the case no subsequent caulking would tighten the joint; the very attempt to do so by caulking had the effect of weakening the joint, and might ultimately result in explosion, as illustrated in a recent instance of a terrible explosion which had caused the loss of seven lives. The first mechanical riveter that he remembered seeing was one which he met with more than thirty years ago at a boiler yard in the Faubourg St. Denis in Paris, and it contained what be considered an improvement of the highest value over some of the present riveting machines. It was a steam riveter, having two steam cylinders working bell-crank levers, one of which had a very sbort stroke and 
carried an annular tool; this did the closing of the plates, holding them pressed together perfectly close, while the riveting die, working within the annular tool, was brought up by the second cylinder and formed the rivet. There was thus no possibility of making a collar between the plates; and it seemed to him some such precaution should always be taken. It was suggested by Mr. Siemens that the olosing of the plates might be done without the second cylinder, by simply actuating the annular closing tool from the riveter itself by means of an elastic oollar. It certainly seemed desirable that the closing pressure on the plates should come before, instead of after, the completion of the rivet. If this were done, it would get rid of caulking, which he had always regarded as a barbarous expedient, tending to separate the plates after the riveter had tried to bring them together. He should like to see all boiler work finished perfectly steam-tight by the riveting machine alone; the plates ought to be in close contact throughout, and not separated as might be caused by the act of caulking, which " upset" the edge of the plate, producing in many places a gap between the plates-a minute gap, it was true, but one sufficient to destroy the close contact requisite for conduction of heat.

In connection with the general question which had been raised as to the conditions affecting the transmission of power by different methods for working a variety of tools, he remembered how about forty years ago the late Mr. Hague, whose apprentice he had been and who had originated the transmission of power by the exhaustion of air, had persuaded the authorities at Woolwich Dockyard to apply, in lieu of shafting, oscillating cylinders to the principal lathes and tools, for driving them by exhaustion, a large exhausting pump being attached to the shop engine. That was however a most unwise application; and the fallacy being fortunately discovered in time, the machines though made were not put up.

The principle of the intensifying accumulator described in the paper was not new, having been practically employed for many years past in the ordinary manufacture of lead piping. A large hydraulic cylinder was used, carrying a ram of rather more than one-fifth the diameter, so that a pressure of 1 ton per sq. in. upon 
the piston was intensified to 18 or 20 tons per sq. in. upon the ram; this ram pressing upon the lead caused it to issue through the die in the form of a pipe. Machines of that description made by Messrs. Easton and Amos had been at work for more than twenty-five years.

The early use of hydraulic power for a variety of mechanical operations at Messrs. Fox and Henderson's works, to which reference had been made, served to illustrate the fact that it was not enough to know the importance of any improvement, but it was necessary to force the conviction of its value into the minds of nnwilling listeners. There was always a natural repugnance to change, where a large amount of capital was invested in existing machinery; and there was consequently little chance of any improvement being extensively adopted, unless some one made its adrocacy his especial business. This was being done by the author of the present interesting paper, which was a continuation of that read by him at the Liverpool meeting; and in the two years which had since elapsed it must be admitted that most satisfactory improvements had been made. A most nseful discussion had been elicited; and he proposed a vote of thanks to Mr. Tweddell for the paper, which was passed.

The following paper was then read:- 
HYDRAULIC MACHINERY. Plate 51.

Fig.1. Stationary Hydrantic Aiveter

for marine boilers bo.

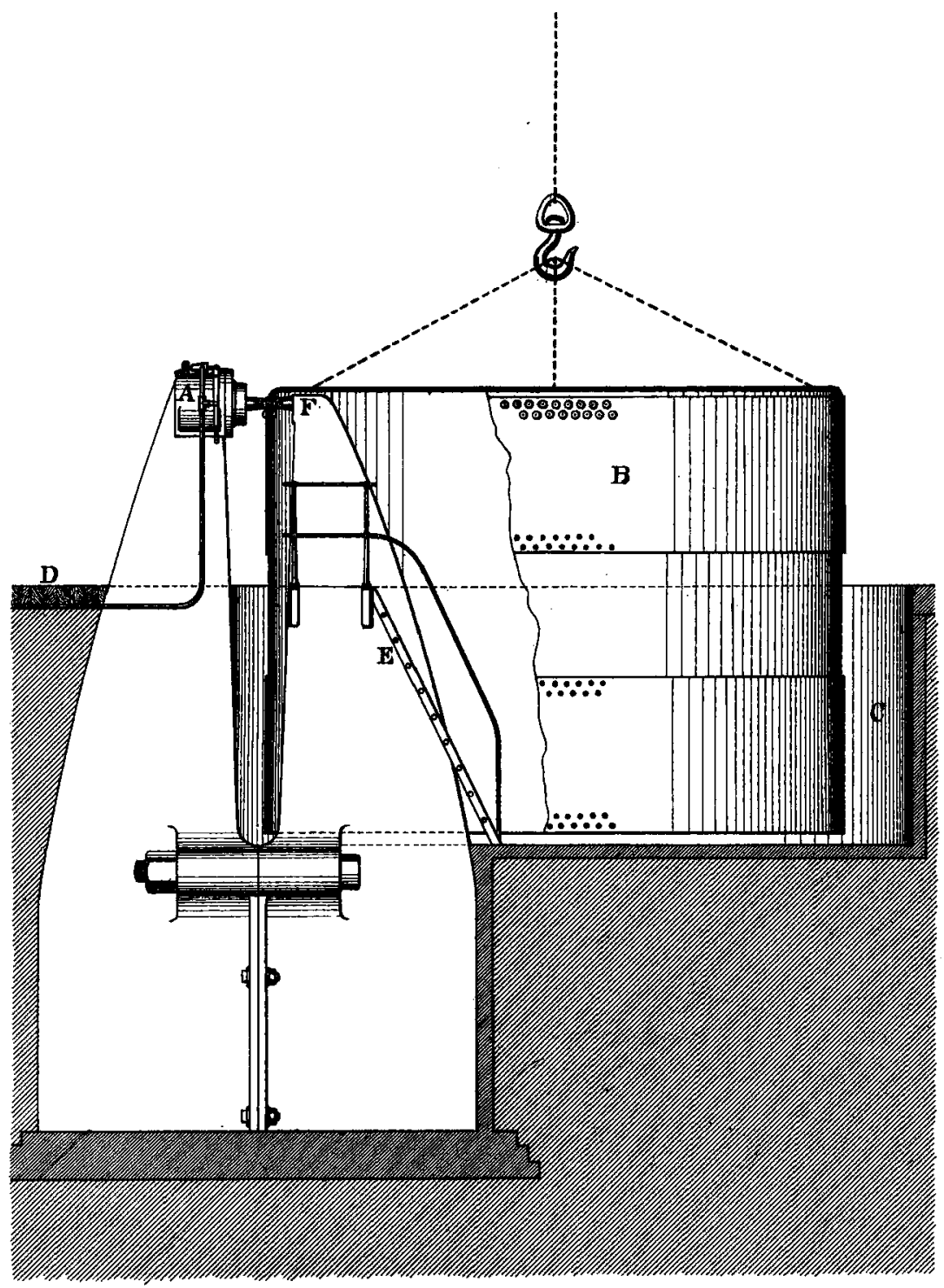

(Procedings Srurt. M. E. 2874)

scale $1 / 60 \stackrel{7 t}{\text { th }}$

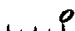


HYDRAULIC MACHINERY.

Plates?.

Fig. 2. Portable Hydrautic Aiveter carried upoon bractoet.

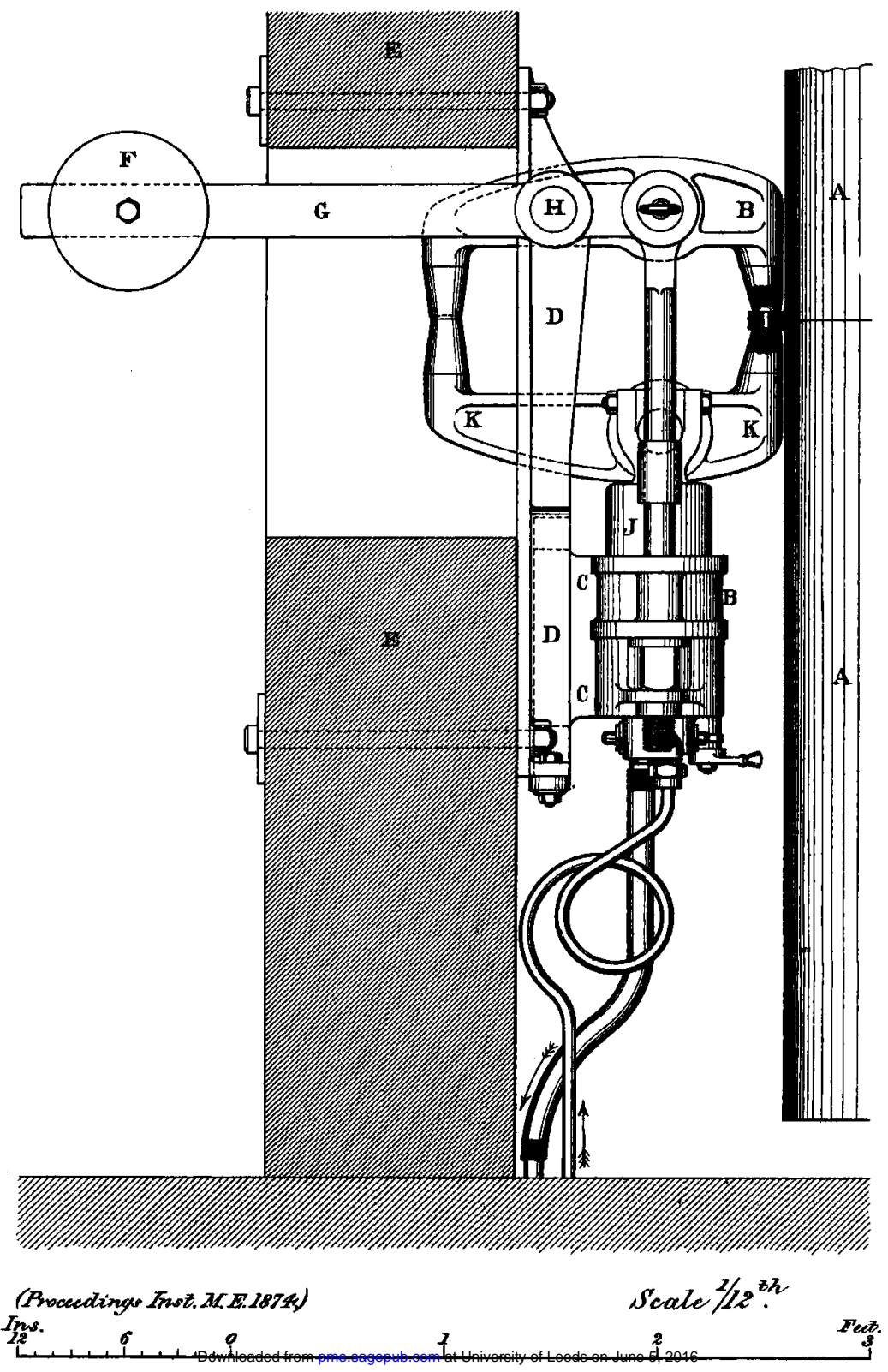


Fig. 3. Portable Hydrautic Riveling Plant.
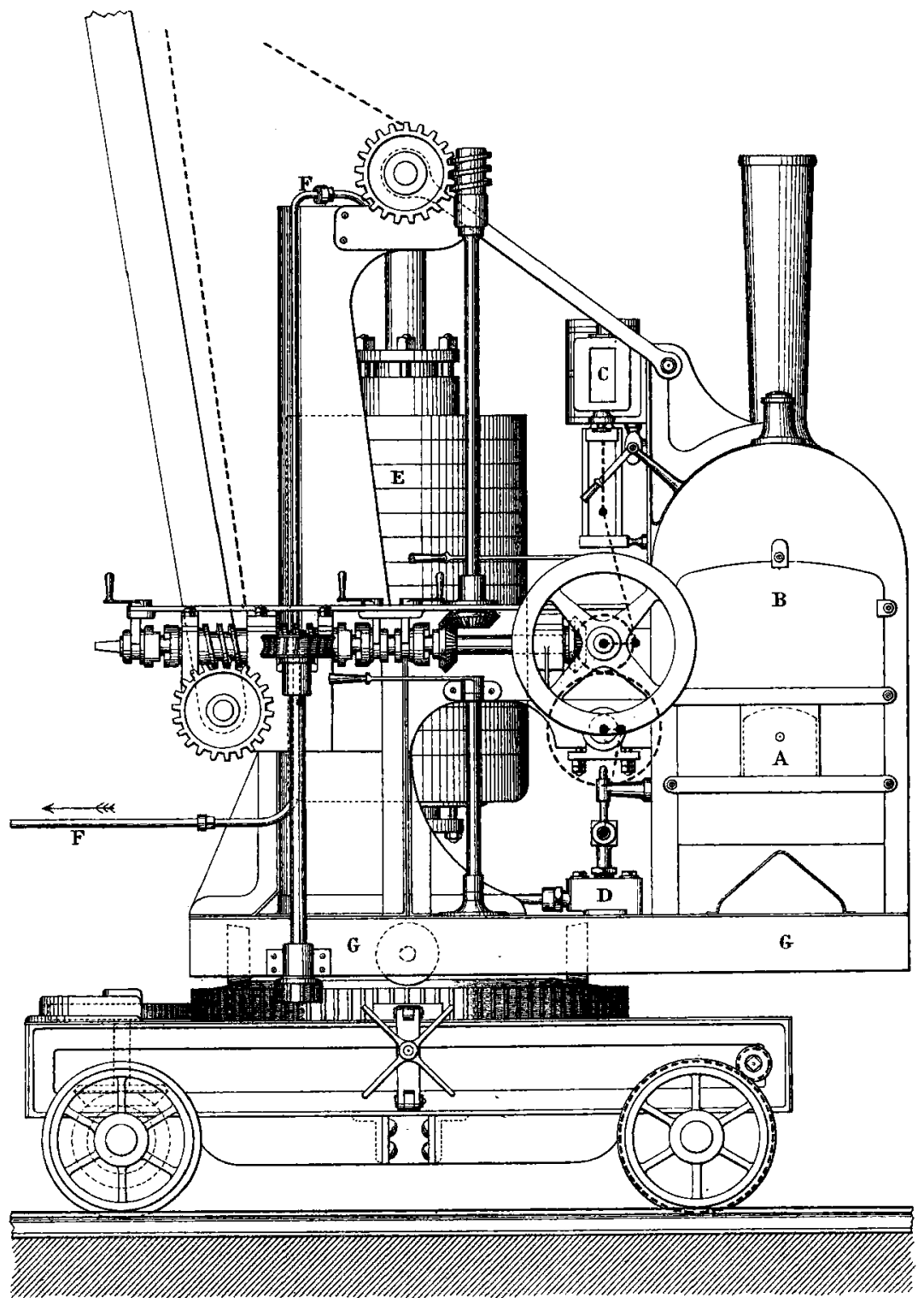

(Proceedings. Inst. M. E. 1874,)

Scale $1 / 30$ th

bus $12 \quad 6 \quad 0 \quad 1$

3 8 Fect. 


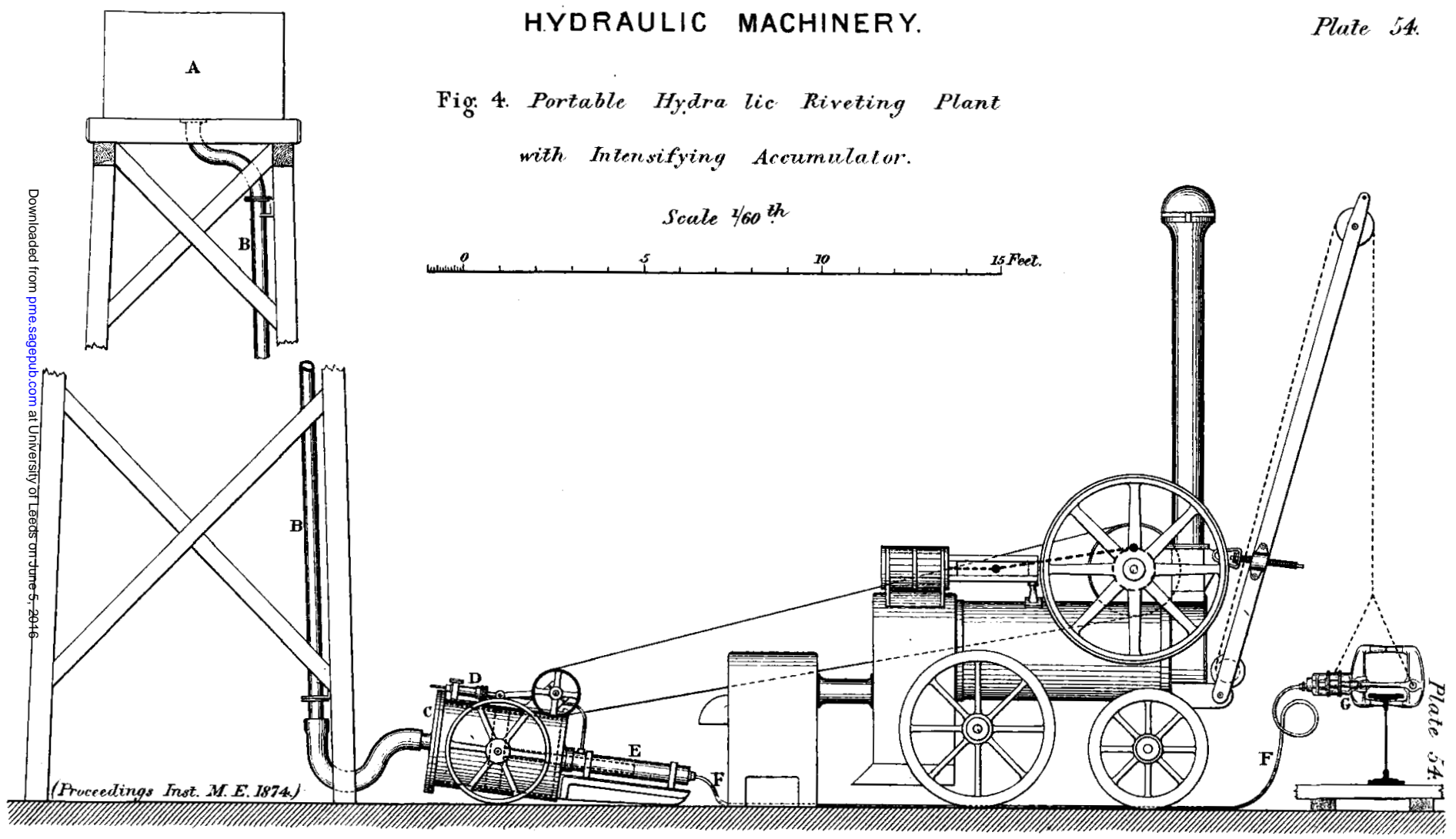


Fig. 5. Hydrautic Flanging Machine.

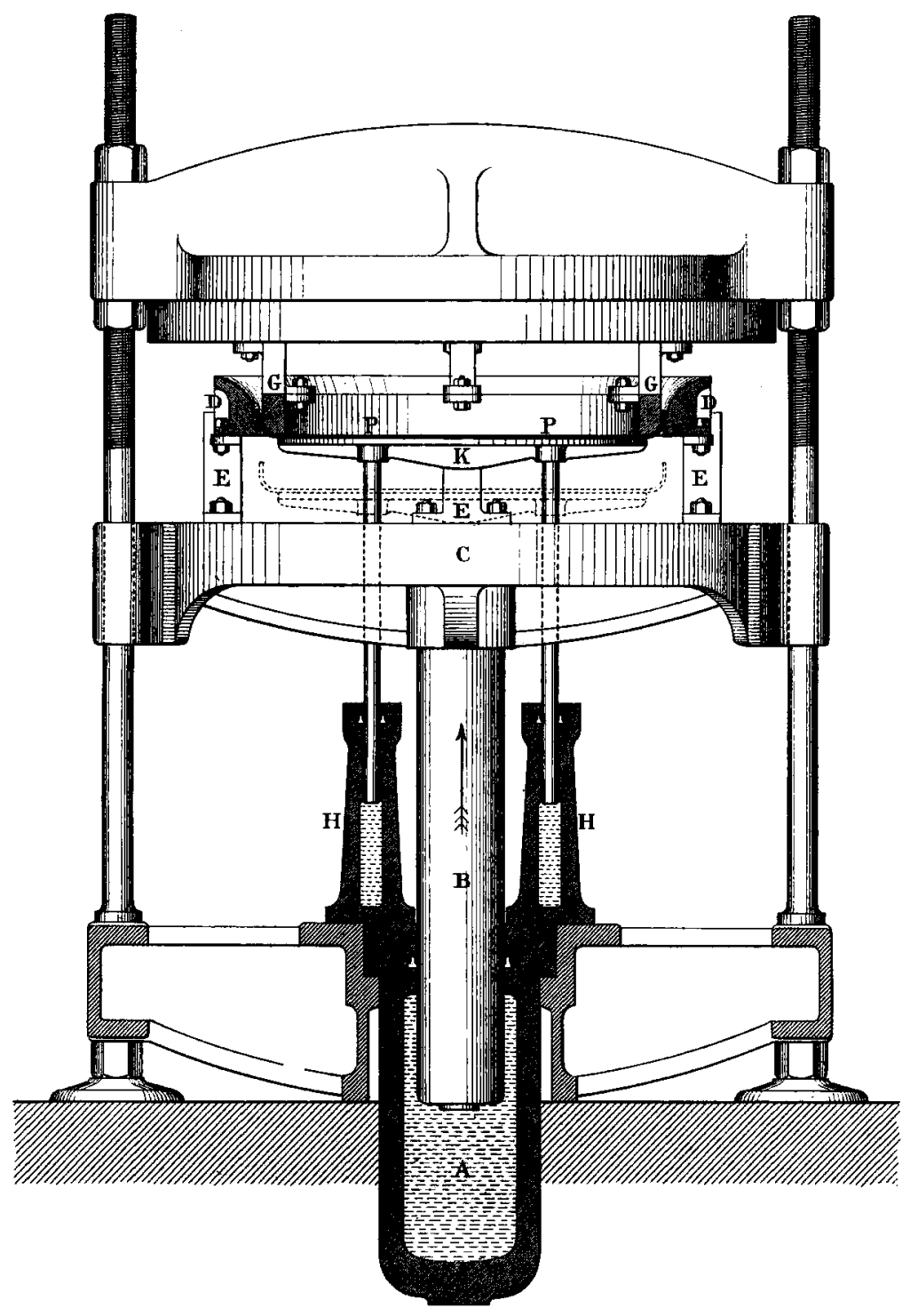




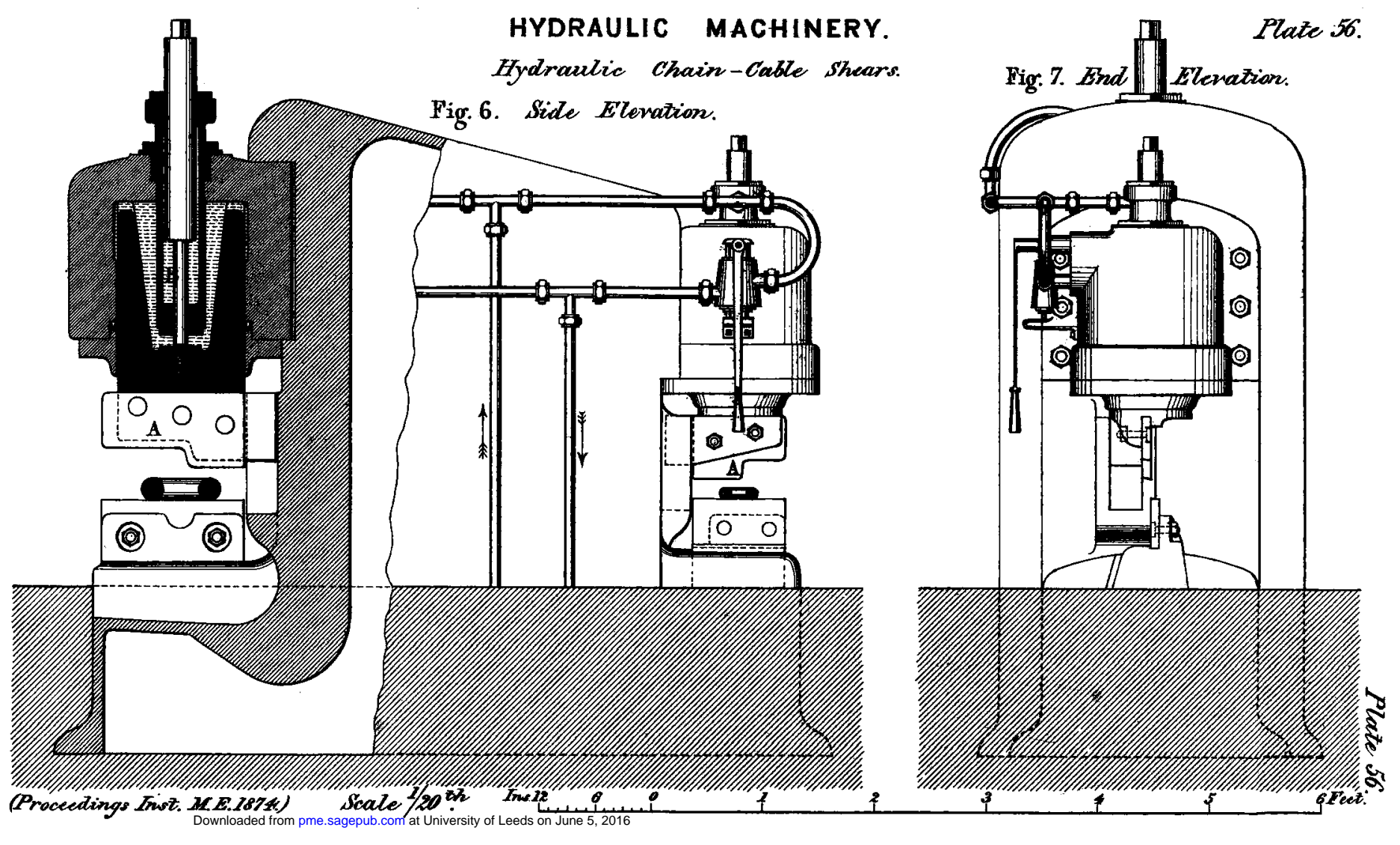


HYDRAULIC MACHINERY.

Hydraulic Punch and Shears.

Fig: 8. Side Elevation.

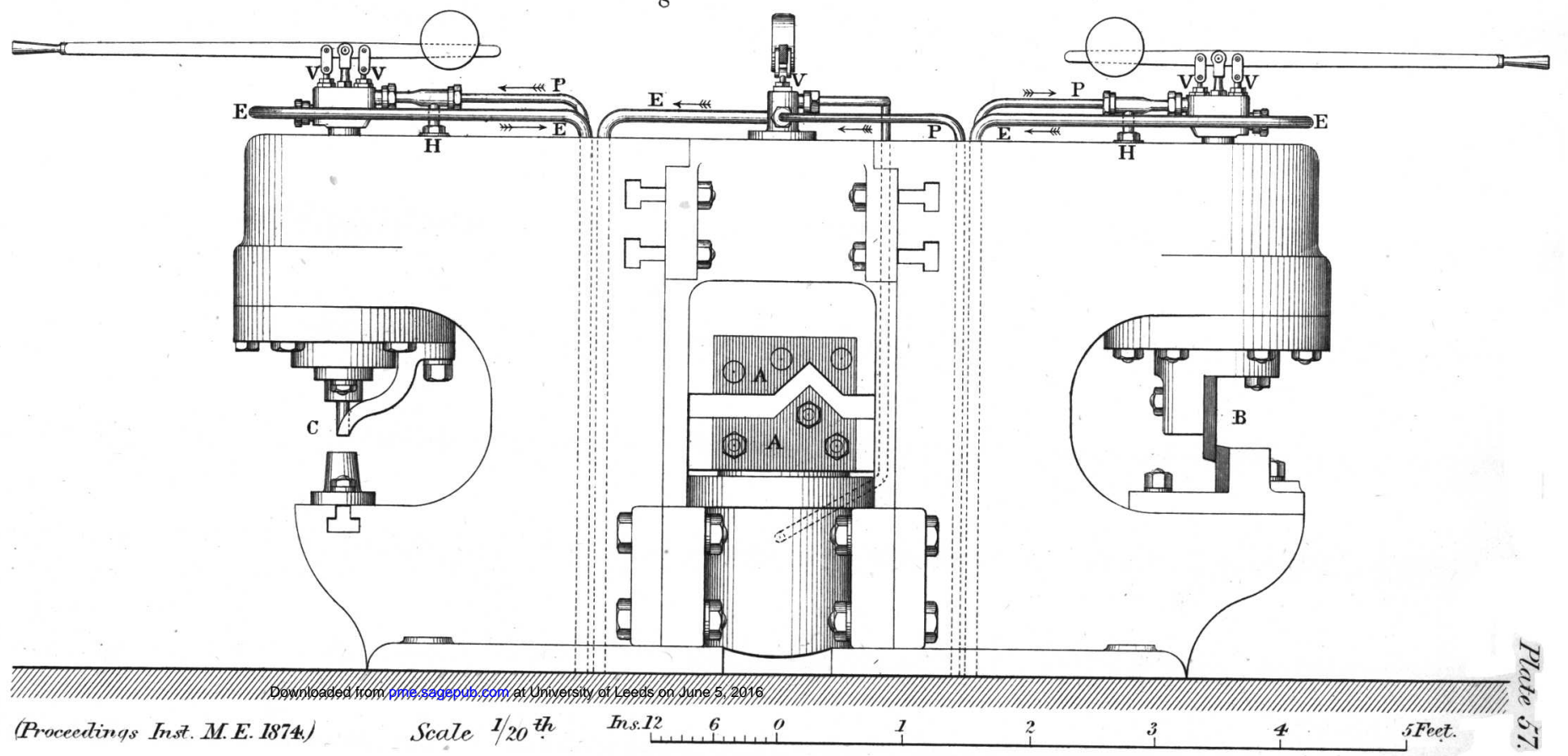


HYDRAULIC MACHINERY. Plate 58 .

InZensifying Accumulator:

Bydraulic Punch and Shears.

Fig: 9. Plan.
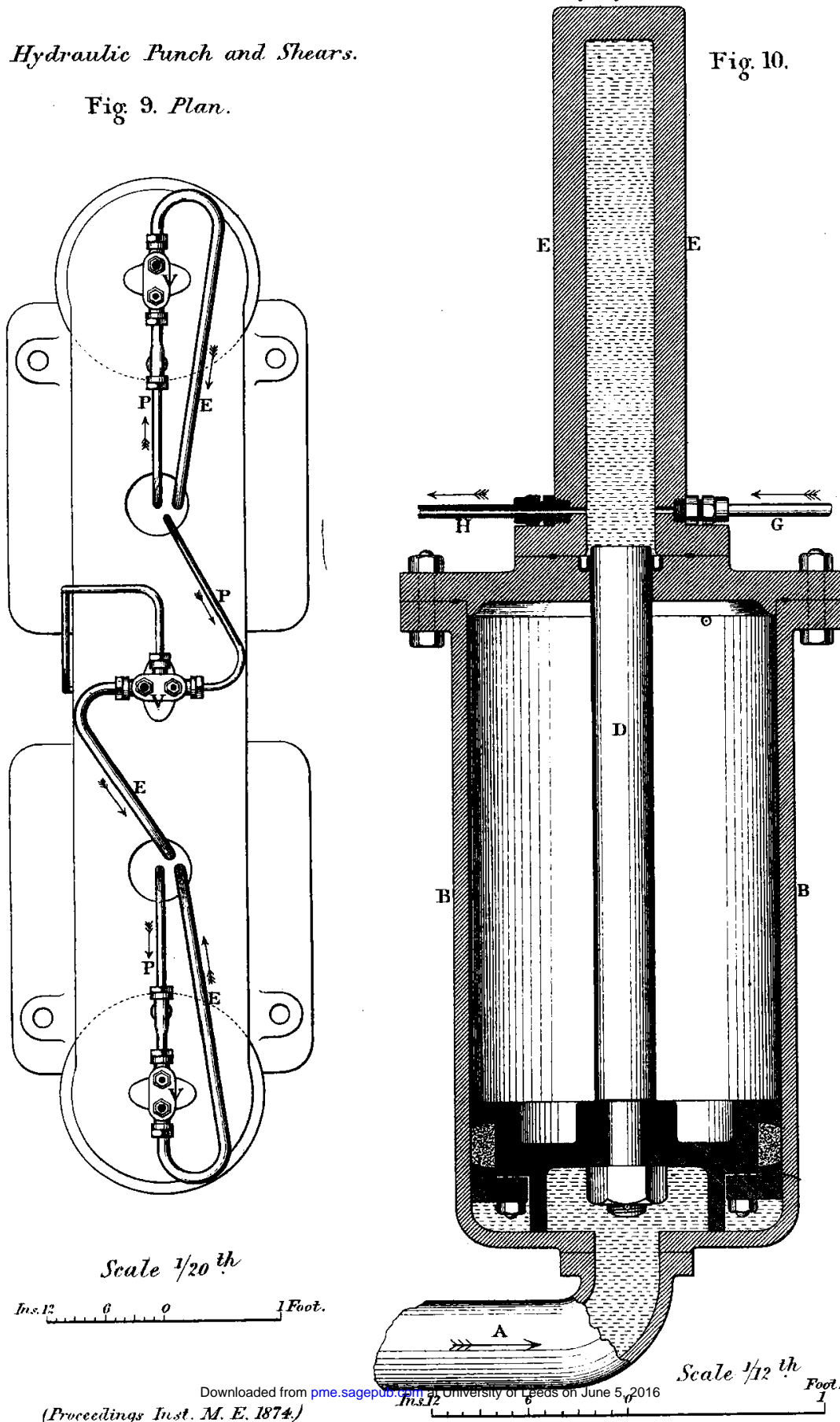
HYDRAULIC MACHINERY.

Hydraulic Corrugating Press.

Fig. 11. Side Elevation.

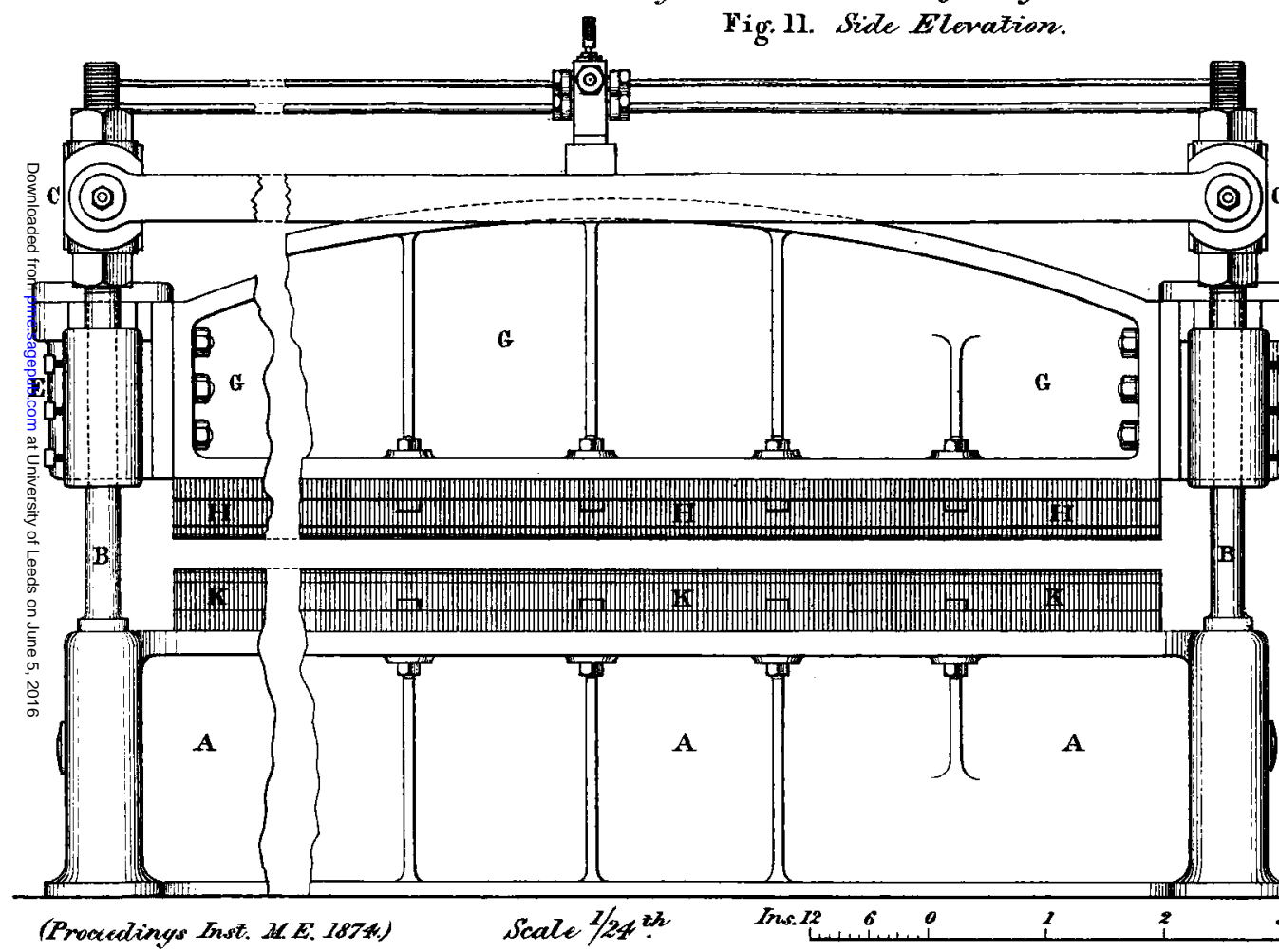

Plate 50.

Fig:12. End Elevation.

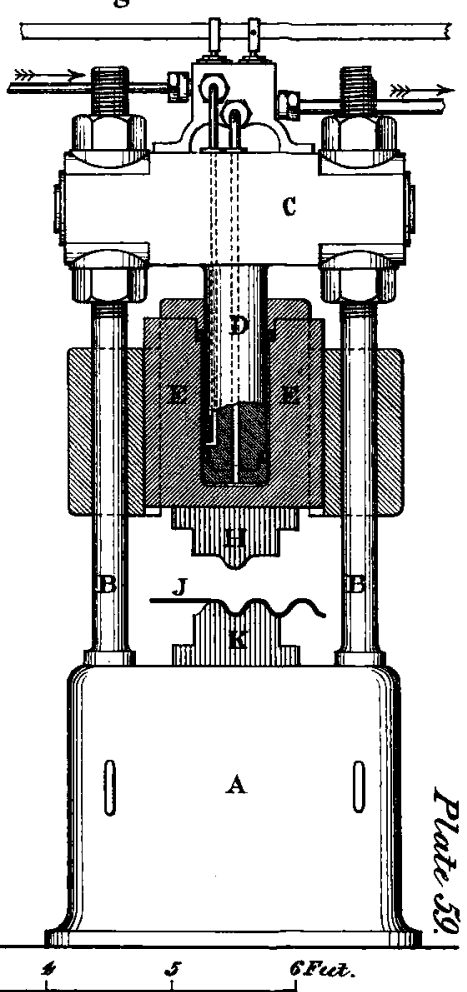


Brotherhood' Three-Cylinder Hydrawlic Engine.

Fig: 13. Longitudinal Section.

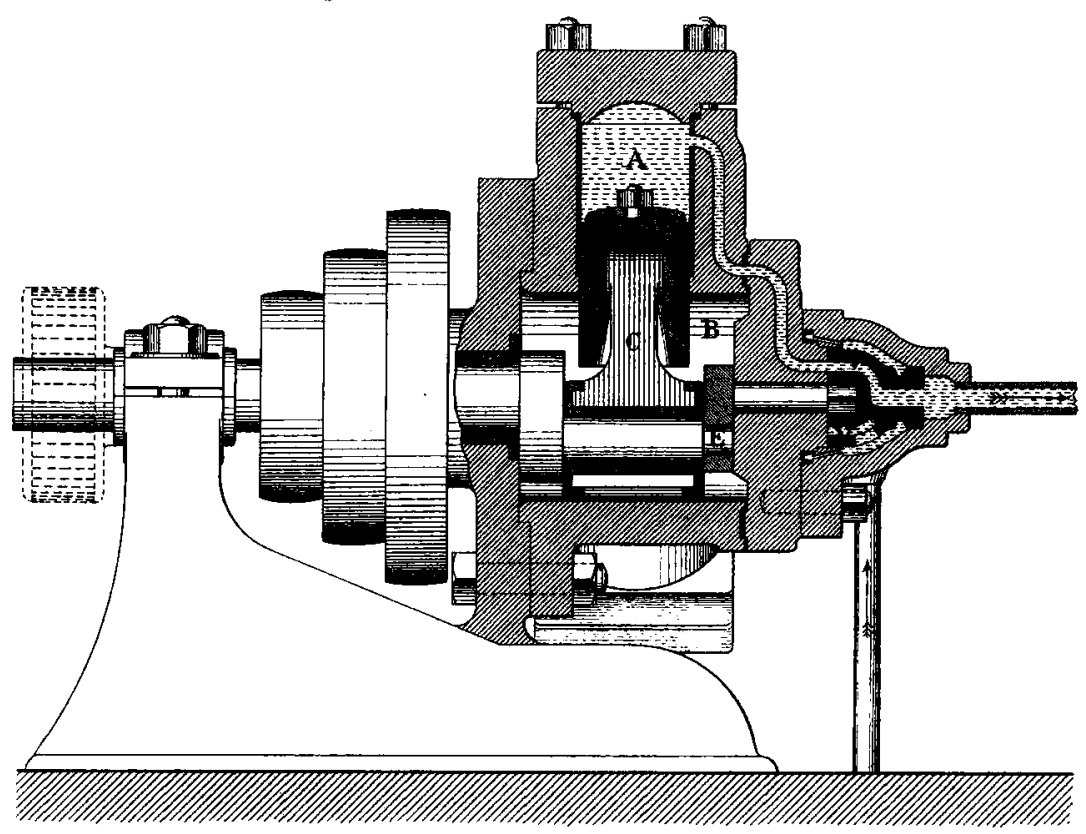

Fig: 14. Transverse Section.

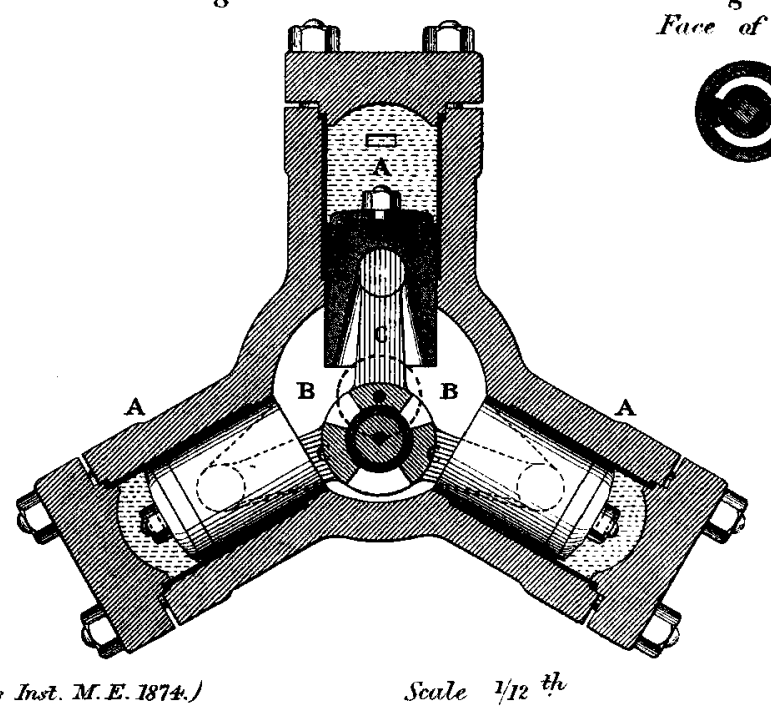

Fig. 15.

are of Valve. 
HYDRAULIC MACHINERY. Plate 61.

Leather Packings for Bydrautic Cytinders.

Fig. 16.

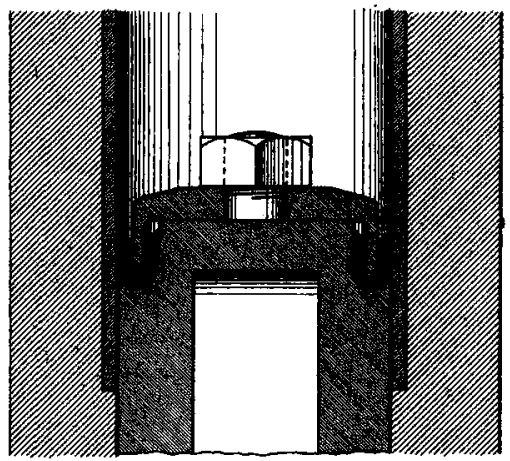

Fig. 17.

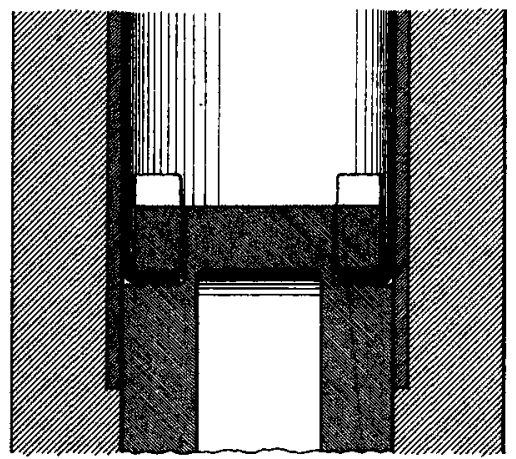

Fig. 18. Netallic Pacting for Hydrautic Plungers.

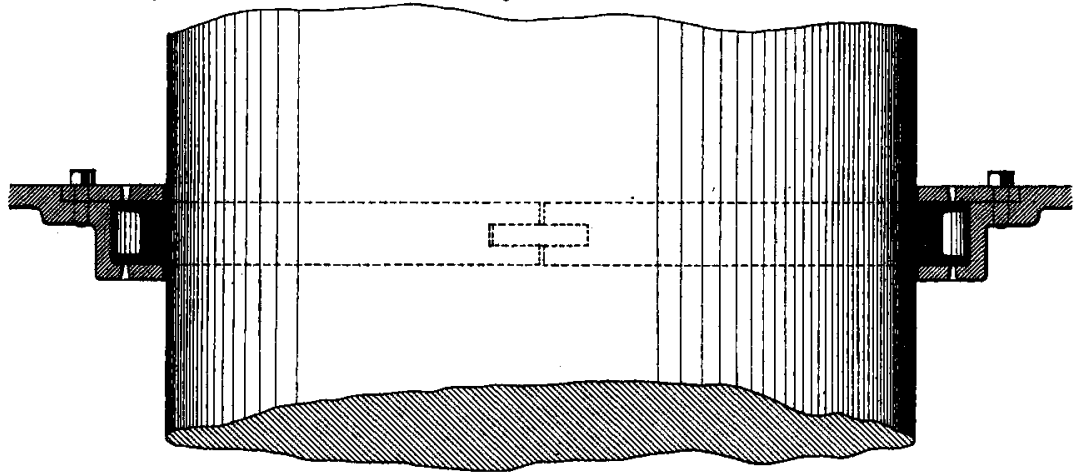

Tig. 19. Metallic Packing for Hydraulic Pistons.

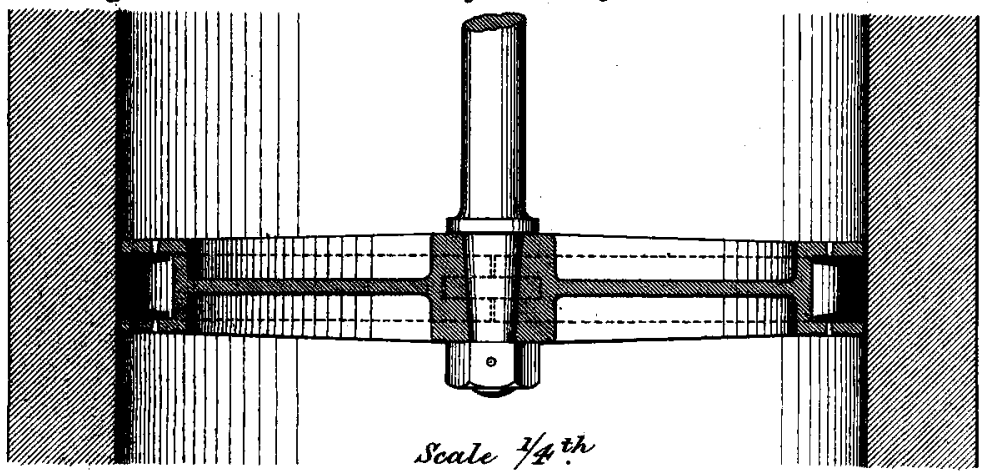

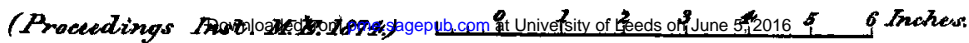

